\begin{tabular}{|c|c|}
\hline Title & $\begin{array}{l}\text { Mitochondrial transgene expression via an artificial mitochondrial DNA vector in cells from a patient with a } \\
\text { mitochondrial disease }\end{array}$ \\
\hline Author(s) & Ishikawa, Takuy a; Somiya, Kana; Munechika, Reina; Harashima, Hideyoshi; Y amada, Y uma \\
\hline Citation & $\begin{array}{l}\text { Journal of controlled release, 274, 109-117 } \\
\text { https://doi.org/10.1016/.jconrel.2018.02.005 }\end{array}$ \\
\hline Issue Date & $2018-03-28$ \\
\hline Doc URL & http:/hdl.handle.net/2115/73334 \\
\hline Rights & $\begin{array}{l}\text { O2018. This manuscript version is made available under the CC-BY-NC-ND } 4.0 \text { license } \\
\text { http://reativecommons.org/icenses/by-nc-nd/4.0/ }\end{array}$ \\
\hline Rights(URL) & http://creativecommons.org/icenses/by-nc-nd/4.0/ \\
\hline Type & article (author version) \\
\hline File Information & WoS_84356_Y amada.pdf \\
\hline
\end{tabular}

Instructions for use 


\section{Mitochondrial transgene expression via an artificial mitochondrial DNA vector in cells from a patient with a mitochondrial disease}

Takuya Ishikawa $^{1,2}$, Kana Somiya ${ }^{1}$, Reina Munechika ${ }^{1}$, Hideyoshi Harashima ${ }^{1}$ and Yuma Yamada ${ }^{1,2, *}$

${ }^{1}$ Faculty of Pharmaceutical Sciences, Hokkaido University, Sapporo, Japan

${ }^{2}$ These authors equally contribute this study.

*To whom correspondence should be addressed:

Kita 12, Nishi 6, Kita-ku, Sapporo 060-0812, Japan

Tel+81-11-706-3735 Fax +81-11-706-3734 E-mail u-ma@pharm.hokudai.ac.jp

Short title (50): Transgene expression in mitochondrial disease cells 


\section{ABSTRACT}

To achieve mitochondrial gene therapy, developing a mitochondrial transgene expression system that produces therapeutic proteins in mitochondria of disease cells is essential. We previously reported on the design of pCMV-mtLuc (CGG) containing a CMV promotor and a NanoLuc (Nluc) luciferase gene that records adjustments to the mitochondrial codon system, and showed that the mitochondrial transfection of pCMV-mtLuc (CGG) resulted in the efficient production of the Nluc luciferase protein in human HeLa cells. This mitochondrial transfection was achieved using a MITO-Porter, a liposome-based carrier for delivering a cargo to mitochondria via membrane fusion. We report herein that mitochondrial transfection using the MITO-Porter results in mitochondrial transgene expression in G625A fibroblasts obtained from a patient with a mitochondrial disease. We investigated the effect of promoters and the basic structure of pCMV-mtLuc (CGG) on gene expression efficiency, and were able to construct a high performance mitochondrial DNA vector, pCMV-mtLuc (CGG) [hND4] that contains a human mitochondrial endogenous gene. We also constructed an RP/KALA-MITO-Porter composed of the KALA peptide (cellpenetrating peptide) with a mitochondrial RNA aptamer to enhance cellular uptake and mitochondrial targeting. Finally, the mitochondrial transfection of pCMV-mtLuc (CGG) [hND4] in G625A fibroblasts using the RP/KALA-MITO-Porter resulted in strong mitochondrial transgene expression.

Keywords: Mitochondria; transgene expression; independent clinical study; mitochondrial disease's patient; mitochondrial delivery; MITO-Porter. 


\section{INTRODUCTION}

The vast majority of diseases of mitochondrial origin result from the incorporation of damaged or mutated proteins into complexes associated with the electron transport chain [1-3]. For example, mitochondrial myopathy, encephalopathy, lactic acidosis and stroke-like episodes (MELAS) are caused by a mutation in protein synthesis in the encoding region of tRNA [4]. MELAS is one of the major mitochondria-related diseases that is responsible for mtDNA mutations, and the major point mutations found in MELAS are localized at bp 3243 (A to G; tRNA ${ }^{\text {Lue }}$ ) [4]. Since various diseases are caused by mutations in mtDNA, mitochondrial gene delivery would be expected to be a viable strategy for curing a mitochondrial disease. To achieve mitochondrial gene therapy, developing a mitochondrial transgene expression system to produce therapeutic proteins in mitochondria of diseased cells is essential.

We previously designed pCMV-mtLuc (CGG) that contains a promoter derived from Cytomegalovirus and a NanoLuc (Nluc) luciferase gene that records adjustments to the mitochondrial codon system (mtLuc (CGG) gene) [5]. As shown in Figure S1A, the pCMV-mtLuc (CGG) contains the CMV promoter, the $N d 4$ gene derived from the mouse mtDNA, mtLuc (CGG) gene and tRNA ${ }^{\text {Asp }}$ with a 5' untranslated region (UTR). The wild-type Nluc luciferase gene can be translated on cytoplasmic ribosomes, but not in mitochondria, because the AGG codon at amino acid 45 (bases 133-135) encodes for Arg in the nuclear genetic code, but in mitochondria, the AGG codon leads to the arrest of mitochondrial translation. While, in the case of the $m t L u c(C G G)$ gene contained in pCMV-mtLuc (CGG), the AGG codon at amino acid 45 (bases 133-135) is changed into a CGG codon which encodes for Arg in both the nuclear genetic and the mitochondrial code. Moreover, the mtLuc (CGG) gene contains a TGA codon at amino acid 12 (bases 34-36), which encodes for mitochondrial Trp and a nuclear genetic stop codon. Therefore, it is not possible for mitochondrial Nluc luciferase to be produced outside mitochondria. We previously confirmed that luciferase activity was detected as the result of the transfection of pCMVmtLuc (CGG) resulting from mitochondrial transgene expression [5]. The positions of point mutations in 
the wild-type Nluc luciferase gene in the design of $m t L u c$ (CGG) are summarized in Table S1. The sequence information is shown in Supplementary Vector sequences (Sequence S1).

Using MITO-Porter system, we also showed that the mitochondrial transfection of pCMV-mtLuc (CGG) resulted in the efficient production of the Nluc luciferase protein in human HeLa cells [5]. The MITO-Porter system is a liposome-based carrier for delivering cargoes to mitochondria via membrane fusion $[6,7]$. This mitochondrial transfection was performed using the KALA-MITO-Porter, which is modified with the KALA peptide, a cationic amphipathic cell-penetrating peptide [8]. As shown in Figure 1, the MITO-Porter is internalized into cells, and the carriers then escape from the endosome into the cytosol. The carriers then bind to mitochondria via electrostatic interactions, and deliver pDNA into mitochondria via membrane fusion. Finally, the pDNA is transcribed to mRNA to produce the protein via translation inside the mitochondrion.

The purpose of this study was to confirm that mitochondrial transfection using the MITO-Porter system can achieve mitochondrial transgene expression in diseased cells. In this study, we used G625A fibroblasts obtained from a patient with a mitochondrial disease. The patient was suffering from MELAS-

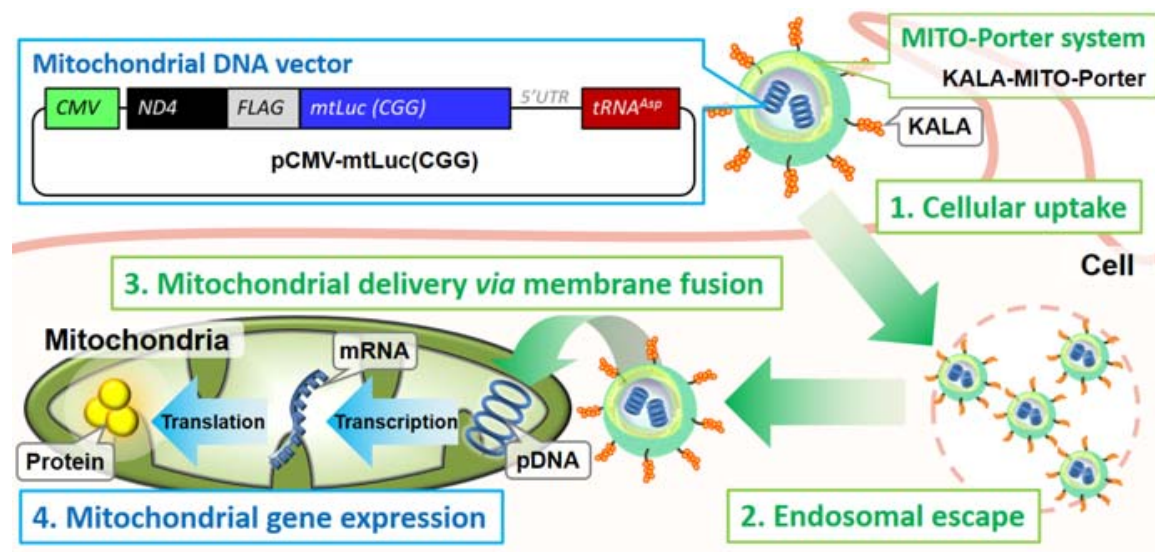

Fig. 1. Schematic illustration of mitochondrial gene delivery using the MITO-Porter system and mitochondrial gene expression. The MITO-Porter is internalized by cells, and the carrier escapes from the endosome into the cytosol. The carrier then delivers pDNA to mitochondria via membrane fusion. Finally, the pDNA was transcribed to mRNA to produce a protein via translation inside the mitochondrion. like symptoms including epilepsy, hearing loss and elevated lactate levels [9]. The G625A fibroblasts carry a heteroplasmic point mutation in the mtDNA localized at bp 625 ( $\mathrm{G}$ to $\mathrm{A})$ coding the tRNA for phenylalanine, leading to a decrease in mitochondrial complex III activity and membrane potential. The positively charged KALAMITO-Porter binds to negatively charged mitochondria via electrostatic interactions. Our initial concern 
was whether the KALA-MITO-Porter could bind to mitochondria of diseased cells, which had a lower mitochondrial membrane potential than those in normal cells. Unfortunately, the mitochondrial transfection of pCMV-mtLuc (CGG) into G625A fibroblasts using the KALA-MITO-Porter or Lipofectamine 2000 (LFN 2000) resulted in no detectable luciferase activity (Figure S1B).

To achieve mitochondrial transgene expression in mitochondrial diseased cells, we constructed a new type of mitochondrial DNA vector and optimized mitochondrial transfection using the KALAMITO-Porter that was modified with a mitochondrial RNA aptamer. We first investigated the effect of promoters and the basic structure of pCMV-mtLuc (CGG) on gene expression efficiency by measuring luciferase activity in an attempt to produce a new mitochondrial DNA vector with a strong mitochondrial transgene expression. Moreover, we constructed an RP/KALA-MITO-Porter with an RNase P (RP) aptamer, a mitochondrial RNA aptamer that enhances cellular uptake and mitochondrial targeting [10]. To monitor the intracellular trafficking of the RP/KALA-MITO-Porter, cellular uptake analysis by flow cytometry and intracellular observation using confocal laser scanning microscopy (CLSM) were performed. Finally, the mitochondrial transfection of pDNA into G625A fibroblasts was performed using the optimized RP/KALA-MITO-Porter, and mitochondrial transgene expression was evaluated by means of a luciferase activity assay. 


\section{EXPERIMENTAL SECTION}

Materials. Cholesteryl hemisuccinate (CHEMS) was purchased from Sigma (St. Louis, MO, USA). 1,2dioleoyl-sn-glycero-3-phosphatidyl ethanolamine (DOPE) and sphingomyelin (SM) were purchased from Avanti Polar lipids (Alabaster, AL, USA). The stearylated moiety that was covalently linked to the Nterm of KALA sequence (WEKLAKALAKALAKHLAKALAKALKA-NH2) (STR-KALA) [11] was obtained from KURABO Industries Ltd (Osaka, Japan). Cholesterol that was covalently linked to the $3^{\prime}$ end of 2'-O-Methyl RNAs containing the RP sequence [5'- UCUCCCUGAGCUUCAGG -3'] (Chol-RP) [10] was obtained from FASMAC Co., Ltd. (Atsugi, Japan). Protamine was purchased from CALBIO CHEM (Darmstadt, Germany). For the visualization of pDNA, Cy5-labeled pDNA was prepared by labeling the molecule with a Mirus Label IT® Cy ${ }^{\mathrm{TM}} 5$ Labeling Kit (Mirus Corp., Madison, WI, USA), according to the manufacturer's recommended protocol. HeLa human cervix carcinoma cells were obtained from the RIKEN Cell Bank (Tsukuba, Japan). Dulbecco's modified Eagle medium with high glucose (DMEM), fetal bovine serum (FBS), LFN 2000 were purchased from Life technologies Corporation (Carlsbad, CA, USA). MitoFluor Red 589 was purchased from Thermo Fisher Scientific Life Sciences (Waltham, MA, USA). Oligonucleotides were purchased from Sigma Genosys Japan (Ishikari, Japan) in purified form. All other chemicals used were commercially available reagent-grade products.

Construction and preparation of pDNA containing an artificially designed gene. The gene fragments for pCMV-mtLuc (CGG), pSV40-mtLuc (CGG), pRSV-mtLuc (CGG), pT7-mtLuc (CGG), pCMVmtLuc (CGG) [hND4], pCMV-mtLuc (CGG) [-ND4] and pCMV-mtLuc (TAG) were synthesized by GENEWIZ (South Plainfield, NJ, USA), and the synthesized genes were inserted into the pBluescript II SK(-) (Stratagene, La Jolla, CA, USA) that had been pretreated with the restriction enzymes (EcoR I and Sma I sites). Sequence information regarding these plasmids is summarized in Supporting Information 
(Sequences S1-S7). The pDNA used in this experiment was amplified in E. coli strain DH5 $\alpha$, purified using an Endfree Plasmid Giga Kit (Qiagen GmbH, Hilden, Germany).

Experimental animals. Male C57BL/6 mice (6 weeks old) that were used in experiments dealing with hydrodynamic injection and male Balb-c mice (4 weeks old) that were used in experiments dealing with evaluating the biocompatibility of the MITO-Porter system were purchased from Sankyo Labo Service (Sapporo, Japan). All animal protocols were approved by the institutional animal care and research advisory committee at the Faculty of Pharmaceutical Sciences, Hokkaido University, Sapporo, Japan (date: 28 March 2016, registration no. 16-0015).

In vivo delivery of pDNA using hydrodynamic injection and an Nluc luciferase assay. To evaluate the efficiency of mitochondrial transgene expression of pDNA, hydrodynamic tail vein (HTV) injection was used to deliver the pDNA to mitochondria of mice livers, as described in a previous report $[12,13]$. To evaluate the extent of the transgene expression of mitochondrial Nluc luciferase in liver tissue, $100 \mu \mathrm{g}$ of naked pDNA in Saline $(2 \mathrm{~mL})$ was injected into the tail vein within a period of $5 \mathrm{sec}$. As previously reported $[5,14]$, at $6 \mathrm{hr}$ post injection, the livers were homogenized using a PreCellys system in $1 \mathrm{~mL}$ of Reporter lysis buffer (Promega), followed by an Nluc luciferase assay using the Nano-Glo Luciferase Assay System (Promega). Protein concentrations were determined using a BCA protein assay kit (Pierce, Rockford, IL). Nluc luciferase activities are expressed as relative light units (RLU) per mg of protein.

Cell cultures. G625A fibroblasts were obtained from a patient with a mitochondrial disease who had been admitted to the Sapporo City General Hospital. The clinical experiments were approved by the Faculty of Pharmaceutical Sciences, Hokkaido University (No. 2014-003 from 2014/10/17), Hokkaido University Hospital (No. 14-061 from 2015/1/1) and Sapporo City General Hospital (No. H26-050-224 from 
2015/1/14). The G625A fibroblasts carry a heteroplasmic mutation in the tRNA for phenylalanine in the mitochondrial DNA, leading to a decreased level of mitochondrial complex III activity and membrane potential. The phenotype includes epilepsy, hearing loss and elevated lactate levels [9]. The cells were maintained in DMEM and 10\% FBS, supplemented with penicillin and streptomycin. Cells were grown in $10 \mathrm{~cm}$ dishes at $37^{\circ} \mathrm{C}$ under $5 \% \mathrm{CO}_{2}$ until reaching approximately an $80 \%$ confluence. Cell passage was performed every 2-4 days. HeLa cells were maintained in complete medium, which is DMEM supplemented with 10\% FBS, penicillin and streptomycin. The cells were cultured under an atmosphere of $5 \% \mathrm{CO}_{2} /$ air at $37^{\circ} \mathrm{C}$.

Packaging of pDNA in MITO-Porter. Condensed particles of pDNA (final DNA concentration, 35 $\mu \mathrm{g} / \mathrm{mL}$ ) were prepared as follows; a solution of pDNA was added to the protamine solution in $10 \mathrm{mM}$ HEPES buffer (pH7.4) under vortexing at a nitrogen/phosphate ratio of 2.3. A lipid film was prepared by the evaporation of a chloroform solution of lipid (DOPE/SM/CHEMS = 9:2:1, molar ratio) on the bottom of a glass tube, follow by hydration with $250 \mu \mathrm{L}$ of a suspension of condensed particles of pDNA for 15 min at room temperature. The glass tube was sonicated for $30 \mathrm{sec}$ in a bath-type sonicator (AU-25C; Aiwa Co., Tokyo, Japan) to package the condensed particles of pDNA in the lipid envelope. The resulting suspension was incubated with STR-KALA (10 mol\% of the total lipids) for $30 \mathrm{~min}$ at room temperature to produce the KALA-MITO-Porter. When the surface of the KALA-MITO-Porter was modified with the RP aptamer, a suspension of KALA-MITO-Porter was added to the Chol-RP solution ( 1 - 6 mol $\%$ of total lipids) in $10 \mathrm{mM}$ HEPES buffer (pH7.4) under vortexing. The $\zeta$-potentials of the resulting particles were measured using Zetasizer Nano ZS (Malvern Instruments, Worcestershire, UK.

Evaluation of the mitochondrial transfection activity of the MITO-Porter in cultured cells. To evaluate the transgene expression of mitochondrial Nluc luciferase, G625A fibroblasts $\left(4 \times 10^{4}\right.$ cells/well $)$ or HeLa cells $\left(4 \times 10^{4}\right.$ cells/well) were seeded on a 24 well plate (Corning) one day before the transfection 
by the MITO-Porter system or LFN 2000. The cells were incubated with carriers containing $0.4-\mu \mathrm{g}$ of pDNA suspended in $0.25 \mathrm{~mL}$ of serum-free DMEM, followed by incubation under an atmosphere of $5 \%$ $\mathrm{CO}_{2}$ at $37^{\circ} \mathrm{C}$ for $3 \mathrm{hr}$. The medium was then replaced with $1 \mathrm{~mL}$ of fresh DMEM containing $10 \%$ serum, followed by incubation for $21 \mathrm{hr}$. LFN 2000 was used according to the manufacturer's recommended protocol. The cells were then washed with phosphate-buffer saline (PBS (-)) and solubilized with reporter lysis buffer (Promega), and the resulting cell lysate was used to estimate the Nluc luciferase activity, as described above.

Evaluation of the cellular uptake of pDNA by flow cytometry. G625A fibroblasts $\left(2 \times 10^{5}\right.$ cells/well $)$ or HeLa cells $\left(1 \times 10^{5}\right.$ cells/well) were seeded on a six-well plate (Corning), and incubated with DMEM, containing $10 \% \mathrm{FBS}$ under an atmosphere of $5 \% \mathrm{CO}_{2} /$ air at $37^{\circ} \mathrm{C}$ for $24 \mathrm{hr}$. Cells were washed with PBS (-) before incubation with the carriers. The cells were incubated with carriers containing 1- $\mu \mathrm{g}$ Cy-5 labeled pCMV-mtLuc (CGG) suspended in $1 \mathrm{~mL}$ of serum-free medium, followed by incubation under an atmosphere of $5 \% \mathrm{CO}_{2}$ at $37^{\circ} \mathrm{C}$ for $1 \mathrm{hr}$. After removing the medium, the cells were washed once with ice-cold PBS (-) and twice with ice-cold PBS (-) containing heparin $(20 \mathrm{U} / \mathrm{mL})$. The cells were trypsinized and then suspended in DMEM with serum. After centrifugation $\left(700 \mathrm{~g}, 4{ }^{\circ} \mathrm{C}, 3 \mathrm{~min}\right)$, the supernatant was removed and cells were resuspended in $0.5 \mathrm{~mL}$ of PBS (-) containing $0.5 \%$ bovine serum albumin (BSA) and $0.1 \% \mathrm{NaN}_{3}$. The cell suspension was filtered through a nylon mesh followed by analysis by flow cytometry (Gallious; Beckman Coulter Inc., Pasadena, CA, USA). Cy5 was excited with a $638 \mathrm{~nm}$ light and the fluorescence detection channel was set to the FL6 filter for Cy5.

Intracellular observation of pDNA transfected by the MITO-Porter. G625A fibroblasts $\left(2 \times 10^{5}\right.$ cells/dish) were seeded on a $3.5 \mathrm{~cm}$ glass-base dish (Iwaki; ASAHI GLASS Company, Ltd., Tokyo, Japan) at one day before transfection and incubated in DMEM, which contained $10 \%$ FBS, under an atmosphere of $5 \% \mathrm{CO}_{2} /$ air at $37^{\circ} \mathrm{C}$. The cells were incubated with carriers containing $1-\mu \mathrm{g} \mathrm{Cy}-5$ labeled 
pCMV-mtLuc (CGG) suspended in $1 \mathrm{~mL}$ of medium without FBS, followed by incubation under $5 \% \mathrm{CO}_{2}$ at $37^{\circ} \mathrm{C}$. After a $1-\mathrm{hr}$ incubation, the medium was replaced with fresh medium containing FBS, and the cells were incubated for $2 \mathrm{hr}$. The medium was replaced with fresh medium containing MitoFluor Red 589 (final concentration, $100 \mathrm{nM}$ ) at $20 \mathrm{~min}$ before the acquisition of fluorescence images, and the cells were incubated in this solution. After this incubation, the cells were washed with phenol red-free medium containing FBS, and then observed by CLSM (FV10i-LIV; Olympus Corporation, Tokyo, Japan). The cells were excited with a $559 \mathrm{~nm}$ light for detecting MitoFluor Red 589 and a $635 \mathrm{~nm}$ light for detecting Cy5 from a LD laser. Images were obtained using an FV10i-LIV equipped with a water immersion objective lens (UPlanSApo 60x/NA = 1.2) and a diachronic mirror (DM 405/473/559/635). The two fluorescence detection Channels (Ch) were set to the following filters: Ch1: BP 570-620 (red color) for MitoFluor Red 589 and Ch2: BP 660-710 (green pseudo color) for Cy5.

Evaluation of the biocompatibility of the MITO-Porter system. Blood was collected from the heart of mice at $24 \mathrm{hr}$ after the administration of PR/KALA-MITO-Porter encapsulating pCMV-mtLuc (CGG) [hND4] via the tail vein injection of $1 \mu \mathrm{g}$ pDNA contained carrier in $50 \mu \mathrm{L}$ of HEPES buffer (pH7.4). Serum was obtained by centrifugation at $1,700 \mathrm{~g}$ for $15 \mathrm{~min}$ at $25^{\circ} \mathrm{C}$. Biochemical marker concentrations were measured by the Oriental Yeast Co., Ltd. (Shiga, Japan). We also evaluated biochemical marker levels in serum obtained from mice that had been administered with HEPES buffer, naked pDNA and the KALA-MITO-Porter encapsulating the pDNA.

Statistical analysis. Data are expressed as the mean \pm S.D. for the indicated number of experiments (Figures 3A, 3B, 4A, 4B, 5, 6B). In Figure 4B, the statistical significances between two groups were examined by the unpaired student's t-test. For multiple comparisons in Figures 3A, 3B, 4A and 5, one way ANOVA followed by bonfferoni test was performed. In Figure 6B, we performed two-way ANOVA 
analysis to compare the effect of two factors that are "pDNA type" and "carrier type". $p<0.05$ was considered to be statistically significant. 


\section{RESULTS}

\section{Design of a mitochondrial DNA vector to express mitochondrial Nluc Luciferase.}

We recently designed a pCMV-mtLuc (CGG) that contains a CMV promotor and an Nluc luciferase gene that records adjustments to the mitochondrial codon system (Figure 2A), and showed that the mitochondrial transfection of the pDNA resulted in a strong mitochondrial gene expression in the liver and in cultured human HeLa cells [5]. However, the transfection of pCMV-mtLuc (CGG) into the G625A fibroblasts obtained from a mitochondrial disease patient resulted in no detectable luciferase activity (Figure S1A). Thus, we focused on the validation of various types of promoters and the basic structure of pCMV-mtLuc (CGG) in an attempt to improve the efficiency of mitochondrial transgene expression in G625A fibroblasts.

To validate the effect of the promoter on mitochondrial gene expression, pSV40-mtLuc (CGG), pRSV-mtLuc (CGG) and pT7-mtLuc (CGG) were designed (Figure 2A). We also used pCMV-mtLuc (CGG) that was reported in a previous study [5] as a control. The pDNAs contain a promoter (CMV, SV40, RSV or T7 promoter), the ND4 gene derived from mouse mtDNA, the mtLuc (CGG) gene that codes mitochondrial Nluc luciferase and tRNA ${ }^{\text {Asp }}$ with the 5'UTR. The CMV, SV40 and RSV promoters are derived from the Cytomegalovirus, the Simian virus 40 and the Rous Sarcoma virus, respectively, all of which have been frequently used to achieve effective nuclear transgene expression in mammalian cells $[15,16]$. We previously reported that the CMV promotor derived from a virus was capable of functioning in mitochondrial transgene expression [5]. The $\mathrm{T} 7$ promoter is derived from the $\mathrm{T} 7 \mathrm{Phage}$, and this promoter is recognized by T7 RNA polymerase, an enzyme that is homologous to mitochondrial RNA polymerase $[17,18]$. Sequence information regarding these promoters is summarized in Table 1.

The pCMV-mtLuc (CGG) contains the $N d 4$ gene derived from mouse mtDNA. To determine whether the $N d 4$ gene is required for mitochondrial gene expression, pCMV-mtLuc (CGG) [-ND4] without the $N d 4$ gene was designed (Figure 2C). We also designed pCMV-mtLuc (CGG) [hND4] containing the $h N d 4$ gene derived from human mtDNA, not mouse mtDNA (Figure 2B), because the 
gene sequence derived from human mtDNA would effectively function in human mitochondria. Sequence information regarding the $N d 4$ gene derived from mouse mtDNA and human mtDNA is shown in Figure 2. We also designed pCMV-mtLuc (TAG) (Figure 2D) containing the mitochondrial/universal stop codon (TAG) in the Nluc luciferase gene as a negative control. The positions of point mutations in the wild-type Nluc luciferase gene in the design of mtLuc (CGG) and mtLuc (TAG) gene are summarized in Table S1. Sequence information regarding these pDNAs shown in Figure 2 can be found in Supplementary Vector sequences (Sequences S1-S7).

A Structure of pCMV-mtLuc (CGG), pSV40-mtLuc (CGG), pRSV-mtLuc (CGG), pT7-mtLuc (CGG)
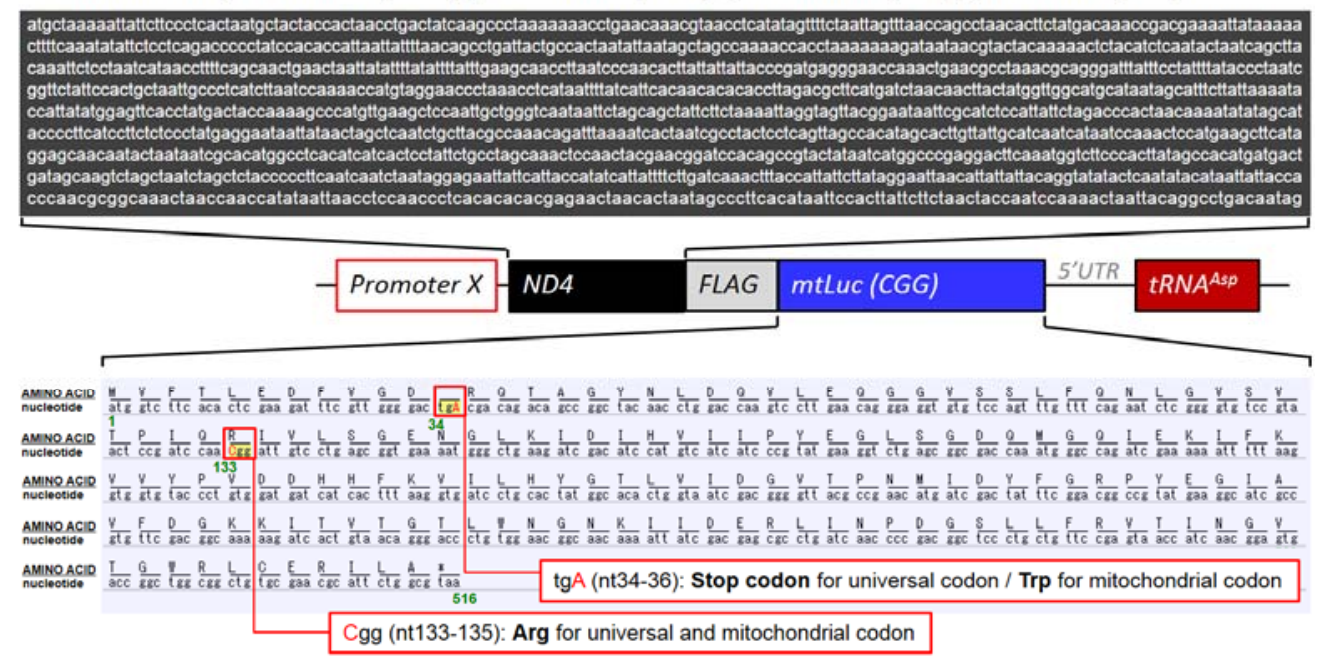

B pCMV-mtLuc (CGG) [hND4]

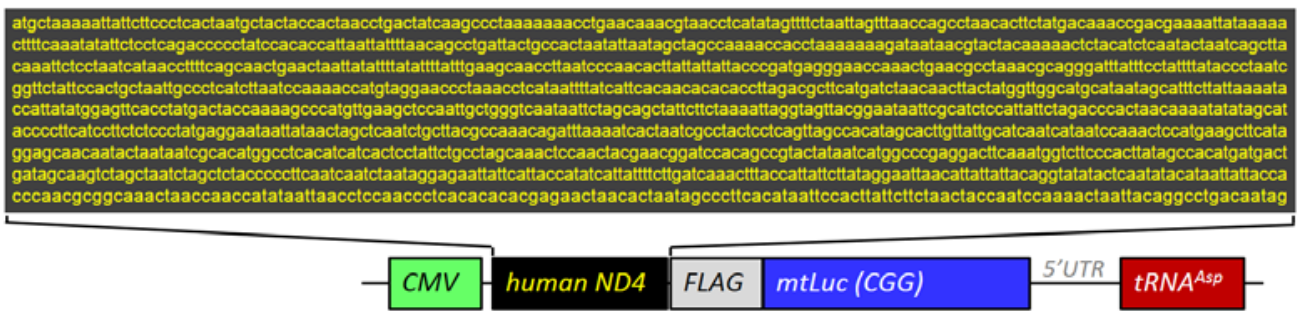

C pCMV-mtLuc (CGG) [-ND4]

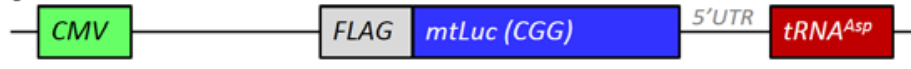

D pCMV-mtLuc (TAG)

\begin{tabular}{|l|l|l|l|}
\hline CMV ND4 & FLAG & mtLUC (TAG) \\
\hline
\end{tabular}

Fig. 2. Design of the pDNA vectors used in this study. The designs of pDNAs with different promoter including pCMV-mtLuc (CGG), pSV40-mtLuc (CGG), pRSV-mtLuc (CGG) and pT7-mtLuc (CGG) are shown (A). The pDNAs contain the promoter (CMV, SV40, RSV or T7 promoter), the ND4 gene derived from mouse mtDNA, the mtLuc (CGG) gene that codes mitochondrial Nluc luciferase and tRNA ${ }^{A s p}$ with the 5'UTR. The pCMV-mtLuc (CGG) [hND4] (B) is different from pCMV-mtLuc (CGG) in terms of containing the $h N D 4$ gene derived from human mtDNA. The pCMV-mtLuc (CGG) [-ND4] (C) is deleted the region of ND4 gene from pCMV-mtLuc (CGG). The pCMV-mtLuc (TAG) (D) contains the mitochondrial/universal stop codon (TAG) in Nluc luciferase gene. 


\section{Evaluation of the transgene expression of the new designed pDNA vector using hydrodynamic}

injection.

To evaluate the transgene expression of the new pDNA vector that was designed based on the structure of pCMV-mtLuc (CGG), we measured the Nluc luciferase activity produced by mice liver mitochondria, after the HTV injection of the pDNAs. HTV injection, in which a large volume of naked pDNA is rapidly injected, is frequently used as an efficient method for the in vivo nuclear delivery of naked pDNA in a wide variety of basic and translational studies [19-21]. We also succeeded in delivering the naked pDNA to the liver mitochondria via HTV injection [13], and showed the HTV injection of pCMV-mtLuc (CGG) resulted in a high expression of the mitochondrial Nluc luciferase protein in the liver [5]. Before evaluating mitochondrial gene expression using cultured cells, we performed an evaluation using HTV injection in order to investigate the abilities of naked pDNA without the carrier among conventional pCMV-mtLuc (CGG) and the new pDNAs.

To validate the effect of the promoter on mitochondrial gene expression, pDNA with different promoters including pCMV-mtLuc (CGG), pSV40-mtLuc (CGG), pRSV-mtLuc (CGG) and pT7-mtLuc (CGG) were administered, and the Nluc luciferase activities in the livers were measured. The findings showed that the Nluc luciferase activity in liver tissue administered by any pDNA (more than $10^{4} \mathrm{RLU} / \mathrm{mg}$ protein) was very high, similar to pCMV-mtLuc (CGG) (Figure 3A). It is noteworthy that the pRSVmtLuc (CGG) showed the highest level of mitochondrial transgene expression. While, previous studies reported that the Nluc luciferase activity for pHSP-mtLuc that contains a mitochondrial endogenous promoter (HSP) was low $\left(10^{3}-10^{4} \mathrm{RLU} / \mathrm{mg}\right.$ protein) [14].

We next compared mitochondrial transgene expression among pCMV-mtLuc (CGG), pCMVmtLuc (CGG) [-ND4] and pCMV-mtLuc (CGG) [hND4] to investigate the requirement of the $\mathrm{Nd} 4$ gene for mitochondrial gene expression (Figure 3B). As a result, we detected a high level of mitochondrial transgene expression of pCMV-mtLuc (CGG) [-ND4], similar to that of pCMV-mtLuc (CGG), suggesting that even pDNA can achieve mitochondrial gene expression, even in the absence of the mitochondrial endogenous gene (Nd 4 gene). While, the mitochondrial gene expression caused by pCMV-mtLuc (CGG) 
[hND4], which contains a human endogenous mitochondrial gene was significantly higher than that by pCMV-mtLuc (CGG), although this evaluation was performed using mice.
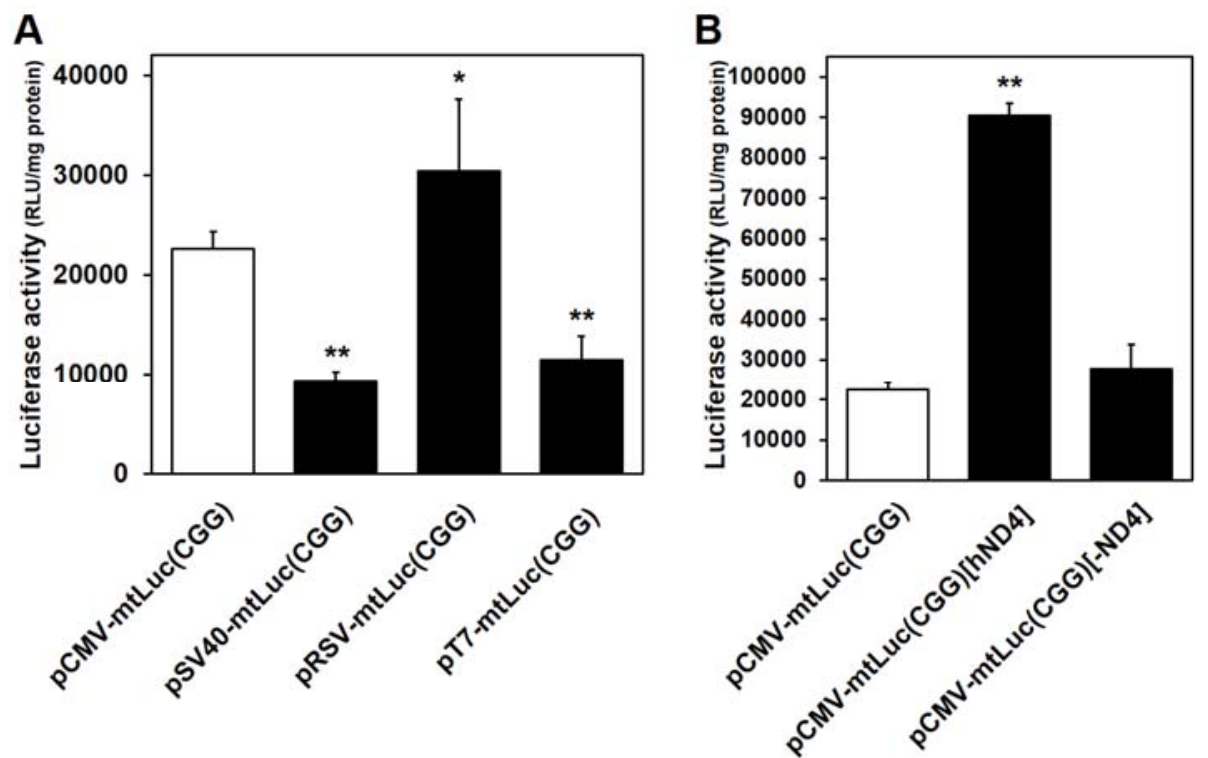

Fig. 3. Evaluation of the transgene expression of the pDNA vector using hydrodynamic injection. (A) A $100 \mu \mathrm{g}$ portion of pCMV-mtLuc (CGG), pSV40-mtLuc (CGG), pRSV-mtLuc (CGG), pT7-mtLuc (CGG) were administered to mice via the tail vein by HTV injection. The livers were harvested at $6 \mathrm{hr}$ postinjection and the Nluc luciferase activities were measured. (B) A $100 \mu \mathrm{g}$ of pCMV-mtLuc (CGG), pCMV-mtLuc (CGG)[hND4], pCMV-mtLuc (CGG)[-ND4], were administered via the tail vein of mice via HTV injection, and the livers were harvested at $6 \mathrm{hr}$ postinjection and the Nluc luciferase activities were measured. Bars represent the means $\pm S D$. ( $n=3)$. **Significant differences (vs pCMV-mtLuc(CGG)) were calculated by onewav ANOVA. followed bv bonfferoni test ( $\mathrm{D}<0.01$ ).

Investigation of mitochondrial gene expression following the mitochondrial transfection of the new designed pDNA vector in human HeLa cells using the KALA-MITO-Porter system.

We evaluated mitochondrial gene expression following the mitochondrial transfection of the new designed pDNA vector, including pSV40-mtLuc (CGG), pRSV-mtLuc (CGG), pT7-mtLuc (CGG) and pCMV-mtLuc (CGG) [hND4] using the MITO-Porter system. In this experiment, we used the KALAMITO-Porter for mitochondrial transfection. To date, we have shown that the mitochondrial transfection of pCMV-mtLuc (CGG) by the KALA-MITO-Porter results in achieving mitochondrial gene expression [5]. The KAKA peptide is a cationic amphipathic cell-penetrating peptide [8], and possesses the property of enhancing mitochondrial transfection, including cellular uptake [5], mitochondrial targeting [22, 23] and mitochondrial membrane fusion [22]. 
As shown in Figure 4A, in HeLa cells, the luciferase activities after the mitochondrial transfection of pDNA with CMV promoter were higher than that for pDNA with other promoters. In particular, pCMV-mtLuc (CGG) [hND4] achieved the highest mitochondrial transgene expression. This result showing that the hND4 sequence enhanced mitochondrial gene expression was also confirmed in an investigation using liver mitochondria via HTV injection (Figure 3B). We also evaluated cell viabilities under the same condition at which mitochondrial transfection was performed using the KALA-MITOPorter (Figure S2A). The findings indicated that there was no difference in cell viabilities among the pDNA types, although, unfortunately, the viabilities of HeLa cells that had been transfected with KALAMITO-Porter were decreased to 50\%.

We next evaluated mitochondrial transgene expression after the mitochondrial transfection of pCMV-mtLuc (CGG) [hND4] by the KALA-MITO-Porter in G625A fibroblasts obtained from a patient with a mitochondrial disease. Before this evaluation, it was confirmed that cell viabilities were not decreased when any of the pDNA types were transfected to mitochondria of G625A fibroblasts by the
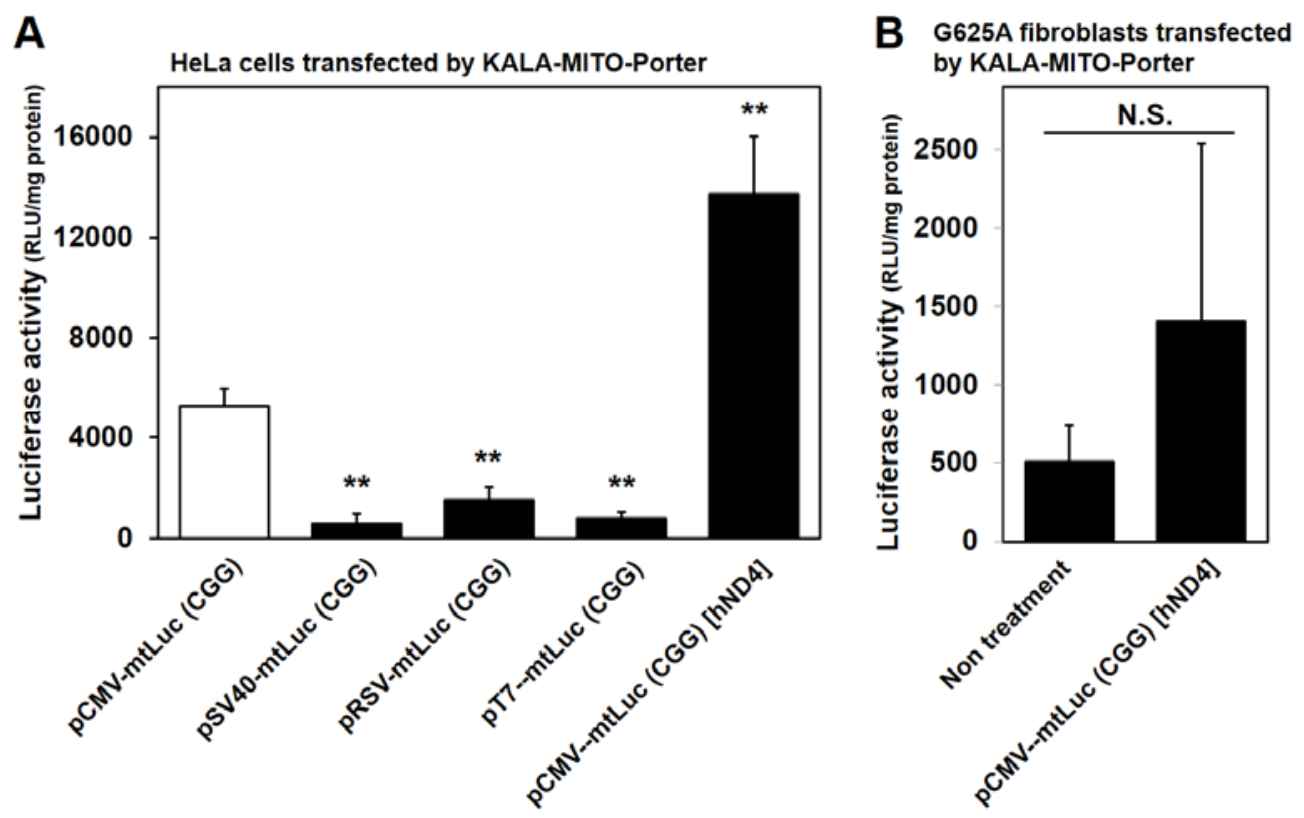

Fig. 4. Investigation of mitochondrial gene expression using the KALA-MITO-Porter. (A) Evaluation of transgene expression in HeLa cells. A $0.4 \mu \mathrm{g}$ of pCMV- mtLuc (CGG), pSV40-mtLuc (CGG), pRSV-mtLuc (CGG), pT7-mtLuc (CGG), pCMV- mtLuc (CGG) [hND4] were transfected to HeLa cells using the KALA-MITO-Porter. After $24 \mathrm{hr}$ transfection, the Nluc luciferase activities were measured. Bars represent the mean $\pm S D$. $(n=3)$. Significant differences (vs pCMV-mtLuc (CGG)) were calculated by one-way ANOVA, followed by bonfferoni test $\left({ }^{* *} p<0.01\right.$ ). (B) Evaluation of transgene expression in G625A fibroblasts. A $0.4 \mu \mathrm{g}$ portion of pCMV- mtLuc (CGG) [hND4] was transfected to G625A fibroblasts using the KALA-MITO-Porter. After $24 \mathrm{hr}$ transfection, the Nluc luciferase activities were measured. Bars represent the mean $\pm S D$. $(n=3)$. No significant difference (N.S.) indicates the lack of a statistically significant difference ( $p>0.05$ by t-test). 
KALA-MITO-Porter (Figure S2B). Unfortunately, the values for the G625A fibroblasts ( 1,500 RLU/mg protein, Figure 4B) were substantially lower compared with the value for HeLa Cells (more than 10,000 RLU/mg protein, Figure 4B). Very low luciferase activities were also detected, when pSV40-mtLuc (CGG), pRSV-mtLuc (CGG) or pT7-mtLuc (CGG) were transfected using the KALA-MITO-Porter, although pCMV-mtLuc (CGG) [hND4] showed the highest mitochondrial gene expression among the other pDNA types (Figure S3). We compared the cellular uptake of pDNA by the KALA-MITO-Porter between G625A fibroblasts and HeLa cells. The findings indicated that the cellular uptake of pDNA by G625A fibroblasts was significantly lower than that by HeLa cells (Figure S4). Based on these results, we concluded that there was a need to improve the KALA-MITO-Porter, if it were to be used for mitochondrial transfection in G625A fibroblasts. 
|Construction of the RP/KALA-MITO-Porter and evaluation of cellular uptake by G625A

\section{fibroblasts.}

The surface of the lipid envelop of the first type of MITO-Porter, referred to as the R8-MITOPorter, was modified with octaarginine (R8) [6]. The R8 functions as both a cellular uptake device functioning via macropinocytosis and as a mitochondrial targeting peptide functioning via electrostatic interactions with negatively charged mitochondria $[6,24,25]$. We recently constructed a dual-ligand modified MITO-Porter composed of R8 with a mitochondrial RNA aptamer (RP aptamer), referred to as a RP/R8-MITO-Porter, and showed that modification with the RP aptamer resulted in an enhanced cellular uptake and mitochondrial targeting in HeLa cells [10]. Thus, we expected that a dual-ligand liposomal system modified with both the RP aptamer and KALA (RP/KALA-MITO-Porter) would show enhanced mitochondrial transfection, even in G625A fibroblasts.

In this study, we prepared a RP/KALAMITO-Porter that contained $10 \mathrm{~mol} \%$ KALA with different levels of RP aptamer. Modification of the positively charged KALA-MITO-Porter with the negatively charged RP aptamer resulted in a reduction in the $\zeta$-potential from a positive charge to a negative charge, and the values became saturated when the modification ratio of RNA-aptamer exceeded $4.0 \mathrm{~mol} \%$ of the total lipids (Figure S5). This indicates that it is possible to attach the RP aptamer to the surface of the KALA-MITO-Porter. We then

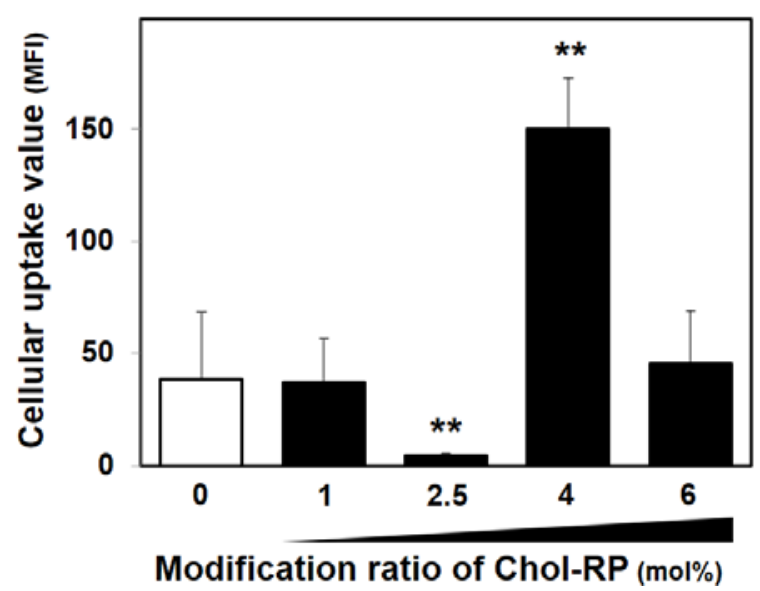

Fig. 5. Evaluating the cellular uptake of $\mathrm{Cy}-5$ labeled pDNA transfected by the RP/KALA-MITO-Porter in G625A fibroblasts by flow cytometry analysis. The cellular uptake values for the KALA-MITO-Porter modified with various ratios of RP (closed columns) and RP-unmodified ones (open columns) are summarized. Data are represented as the mean \pm S.D $(n=3)$. Significant differences (vs RP-unmodified KALA-MITO-Porter) were calculated by one-way ANOVA, followed by bonfferoni test $\left({ }^{* *} p<0.01\right)$.

investigated the effect of modification with the RP aptamer on the cellular uptake of the KALA-MITOPorter in G625A fibroblasts. Figure 5 shows data for the cellular uptake of the Cy-5 labeled pDNA encapsulated in MITO-Porter. As a result, modifying the KALA-MITO-Porter with 4 mol\% of the RP 
aptamer resulted in a significant increase in cellular uptake compared with the RP-unmodified KALAMITO-Porter. In the following studies, the surface of the KALA-MITO-Porter was modified with $4 \mathrm{~mol} \%$ of the RP aptamer.

\section{Mitochondrial transfection of pCMV-mtLuc (CGG) [hND4] into G625A fibroblasts using the RP/KALA-MITO-Porter and evaluation of mitochondrial transgene expression.}

To investigate the mitochondria transfection activity of the RP/KALA-MITO-Porter in G625A fibroblasts, we measured the luciferase activities resulting from the transgene expression of the mitochondrial Nluc luciferase protein following the mitochondrial transfection of pCMV-mtLuc (CGG) [hND4] using the RP/KALA-MITO-Porter or the KALA-MITO-Porter. Before measuring Nluc luciferase activity, the intracellular localization of these carriers with the Cy-5 labeled pDNA encapsulated was observed by CLSM (Figure 6A). In the case of the RP/KALA-MITO-Porter, numerous green and some yellow dots were observed in cells (Figure 6A (a)), indicating that the Cy5-labeled pDNAs (pseudo green color) were mainly localized in the cytosol and some pDNAs were localized in red-stained mitochondria. When the KALA-MITO-Porter was used, some yellow signals were observed (Figure 6A (b)).

As shown in Figure 6B (closed bars), the transfection of pCMV-mtLuc (CGG) [hND4] by RP/KALA-MITO-Porter resulted in a high Nluc luciferase activity (more than 20,000 RLU/mg protein), while the value for the KALA-MITO-Porter was very low, comparable to the value for naked pDNA. We also performed the mitochondrial transfection of pCMV-mtLuc (TAG), which contains the mitochondrial/universal stop codon (TAG), as a negative control experiment. No Nluc luciferase activity was detected in the case of any of these carriers, as shown in Figure 6B (open bars). We performed 2-way ANOVA analyses to compare the effect of two factors, i.e., "pDNA type" and "carrier type". There were significant differences between the "pDNA type" ( $p<0.001)$ and "carrier type" $(\mathrm{p}<0.001)$, as well as a significant interaction between 2 factors $(p<0.001)$. The use of a simple main effect test indicated the existence of significant differences between the pCMV-mtLuc (CGG) [hND4] and pCMV-mtLuc (TAG) 
in the case of RP/KALA-MITO-Porter $(* * * p<0.001)$. Based on these findings, we conclude that the $\mathrm{RP} / \mathrm{KALA}-\mathrm{MITO}-\mathrm{Porter}$ is required for the mitochondrial transfection of pCMV-mtLuc (CGG) [hND4] to achieve mitochondrial transgene expression in G625A fibroblasts.

A

(a) KALA-MITO-Porter

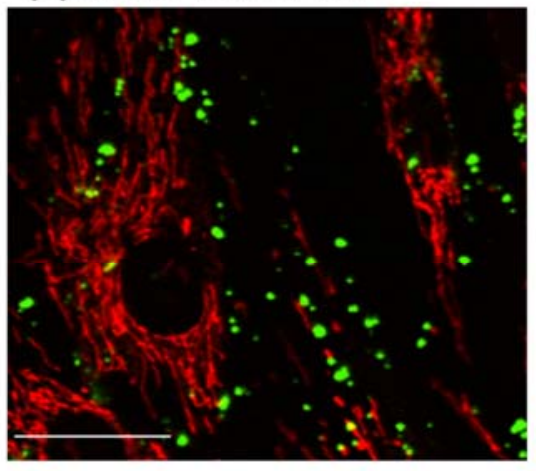

(b) RP/KALA-MITO-Porter

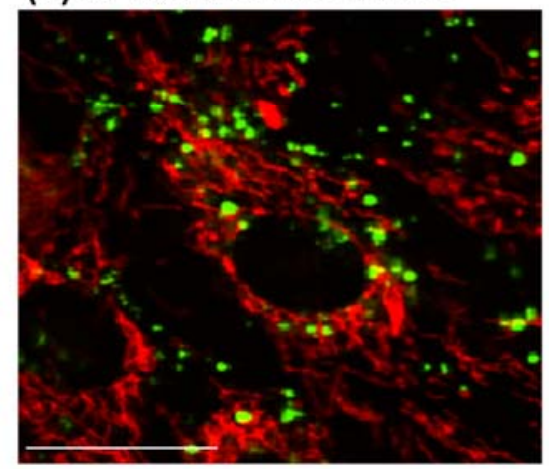

B
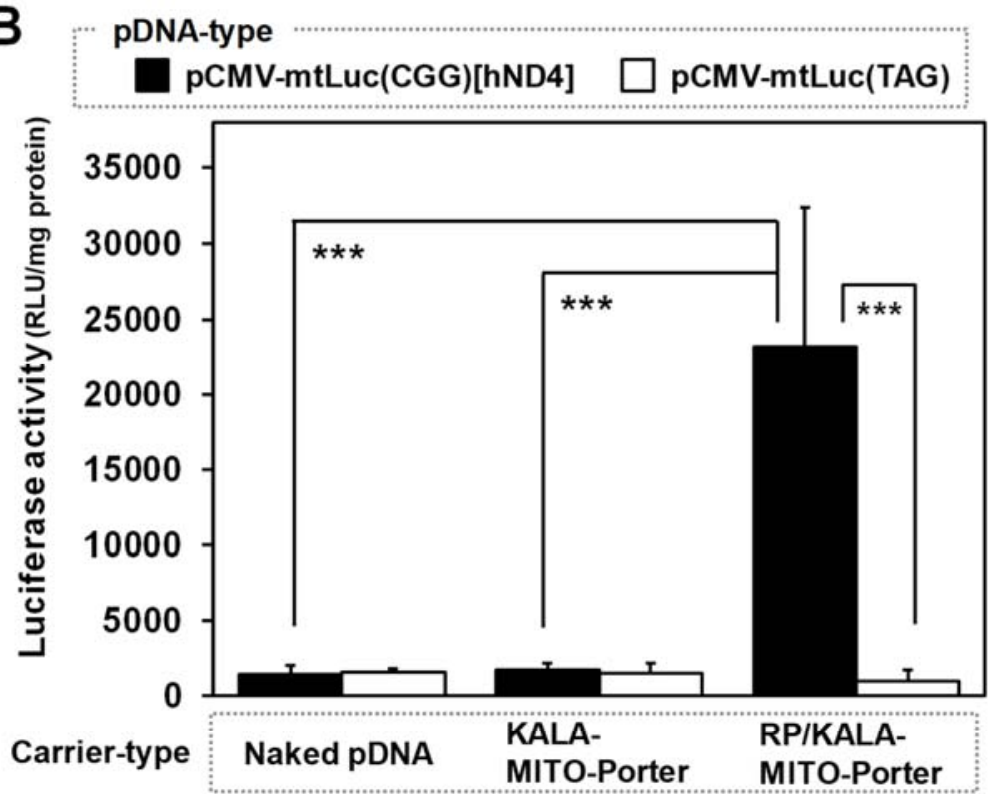

Two way ANOVA analysis result

\begin{tabular}{lc}
\hline Factors & P-value by two way ANOVA \\
\hline pDNA-type & $<0.001$ \\
Carrier-type & $<0.001$ \\
Interaction between two factors & $<0.001$ \\
\hline
\end{tabular}

Fig. 6. Comparison of mitochondrial transfection between the KALA-MITO-Porter and the RP/KALA-MITOPorter. (A) Intracellular observation using CLSM after pDNA transfection by KALA-MITO-Porter (a) and RP/KALA-MITO-Porter (b). Cy-5 labeled pCMV-mtLuc (CGG) (pseudo green color) is seen to colocalize with red-stained mitochondria in G625A fibroblasts, observed as yellow signals in the merged image. (For interpretation of the references to colour in this figure legend, the reader is referred to the web version of this article.) Scale bars; $30 \mu \mathrm{m}$. (B) Evaluation the transgene expression of pCMV-mtLuc (CGG) [hND4]. G625A fibroblasts were transfected with $0.4 \mu \mathrm{g}$ of pCMV- mtLuc (CGG) [hND4] or pCMV- mtLuc (TAG) using the KALA-MITO-Porter, the RP/KALA-MITO-Porter and the absence of a carrier. Nluc luciferase activities were measured at $24 \mathrm{hr}$ after transfection. Bars represent the mean $\pm S D$. $(n=3)$. Two-way ANOVA analysis was performed to compare the effect of two factors that are "pDNA type" and "carrier type". Because there was significant interaction between 2 factors, simple main effect test also performed. ${ }^{* * *}$ significant differences ( $p<0.001$ by simple main effect test, followed by Bonferroni correction).

To evaluate biocompatibility of the RP/KALA-MITO-Porter, we investigated the viability of G625A fibroblasts when mitochondrial transfection was performed using the RP/KALA-MITO-Porter

(Figure S6). As result, the relative cell viabilities transfected with naked pDNA and the RP/KALAMITO-Porter encapsulating the pDNA were comparable, indicating that mitochondrial transfection using the RP/KALA-MITO-Porter did not decrease the viability of G625A cells. Moreover, we measured 
biochemical marker levels in serum at $24 \mathrm{hr}$ after the administration of the RP/KALA-MITO-Porter to mice (Table 2). No significant differences were found between the saline administered mice and the carrier administered mice. 


\section{DISCUSSION}

To develop practical applications of mitochondrial gene therapy via the mitochondrial transfection of a mitochondrial DNA vector, it is essential to demonstrate that the mitochondrial transfection methodology is capable of achieving mitochondrial transgene expression in patient-derived disease cells. We previously reported that mitochondrial transfection by the KALA-MITO-Porter results in achieving mitochondrial gene expression in human HeLa cells [5]. However, we were concerned as to whether the positively charged KALA-MITO-Porter, which binds to negatively charged mitochondria via electrostatic interactions, would be capable of targeting mitochondria of diseased cells. This concern stems from the fact that the mitochondrial function of mitochondria in diseased cells is decreased, including a decrease in mitochondrial membrane potential. In fact, the mitochondrial membrane potentials of G625A fibroblasts used in this study were low (data not shown).

Unfortunately, the mitochondrial transfection into G625A fibroblasts by the KALA-MITO-Porter resulted in no detectable luciferase activity (Figures S1, S3). Given this situation, we attempted to use an RP aptamer, which is a negatively charged mitochondrial RNA aptamer that can enhance mitochondrial targeting, as a mitochondrial targeting ligand of the KALA-MITO-Porter. Our previous studies showed that modification of the R8-MITO-Porter with the RP aptamer enhanced cellular uptake and mitochondrial targeting in HeLa cells [10]. As shown in Figure 5, modification of the KALA-MITO-Porter with 4 mol\% of the aptamer caused a significant increase in the cellular uptake values compared with the RPunmodified KALA-MITO-Porter.

Considering that the RP aptamer itself does not have cellular uptake activity, this result indicates that the RP aptamer coats the entire surface of the KALA-MITO-Porter, with the head group of KALA being displayed on the RP aptamer coated carrier-surface, and a part of the KALA could then induce cellular uptake. Certain quantities of RP aptamer are required to change the surface charge of the carrier to negative are necessary for enhancing cell uptake. In the case of the RP/KALA-MITO-Porter, a more than 4.0 mol \% modification with the RP aptamer is needed to show a negative zeta potential (Figure S5). 
In this scenario, KALA might be displayed on the MITO-Porter in a topology favorable to cellular uptake when it was modified at optimal amounts of the RP aptamer (4.0 mol\%). The use of an excess amount of RNA aptamer (6.0 mol\%) might mask, even the head group of the KALA displayed on the RP aptamer coated carrier-surface, resulting in a decrease in cellular uptake. Such an optimal value was also observed when the RP/R8-MITO-Porter was used in the case of HeLa cells [10]. We speculate that the cellular uptake decreased at a 2.5\% RP aptamer modification, because the charge was neutralized (Figure S5), so that the stability of the carriers decreased and aggregation easily occurred in the culture medium. In the following studies, the surface of the KALA-MITO-Porter was modified with 4 mol\% of the RP aptamer.

Intracellular observations (Figure 6A) showed that, in G625A fibroblasts, the RP/KALA-MITOPorter accumulated in mitochondria more efficiently than the KALA-MITO-Porter, although the KALAMITO-Porter showed efficient mitochondria targeting in HeLa cells [5]. These findings suggest that mitochondrial specific delivery via the RP aptamer of the RP/KALA-MITO-Porter is necessary for G625A fibroblasts, which have low mitochondrial membrane potentials, rather than by mitochondrial delivery by the KALA-MITO-Porter via electrostatic interactions. We previously found a similar phenomenon wherein a RP-modified R8-MITO-Porter accumulated in mitochondria more efficiently than a RP-unmodified one [10]. Collectively, we conclude that RP aptamer modification enhanced both the cellular uptake and mitochondrial targeting of the KALA-MITO-Porter in G625A fibroblasts, contributing to the enhancement of mitochondrial transfection in G625A fibroblasts.

We also attempted to improve the mitochondrial transgene expression efficiency of pCMV-mtLuc (CGG) in G625A fibroblasts by varying the promoters used and the basic structure of the pDNA. To improve the mitochondria DNA vector, we used HTV injection, in which the naked pDNA is delivered to liver mitochondria, before the cell experiment, because we were interested in investigating the potential for the naked pDNA without a carrier among conventional pCMV-mtLuc (CGG) and the new designed 
pDNAs. The findings indicated that the pCMV-mtLuc (CGG) [hND4] showed the highest level of mitochondrial transgene expression (Figure 3).

Similarly, the mitochondrial transfection of HeLa cells with the pCMV-mtLuc (CGG) [hND4] by the KALA-MITO-Porter showed the highest mitochondrial transgene expression (Figure 4A). These results indicate that the optimal type of promoter needed for mitochondrial gene expression was different between mouse liver and HeLa cells. In studies targeting the nucleus, it has been reported that the sequence of the promoters used affects the efficiency of gene expression and that this process is dependent on the cell-type used [16]. We also found that the hND4 sequence has a greater effect on mitochondrial gene expression than the promoter-types.

While, in the case of G625A fibroblasts, mitochondrial transgene expression efficiency by the mitochondrial transfection of pCMV-mtLuc (CGG) [hND4] was not significantly higher than that of other pDNAs when the KALA-MITO-Porter was used (Figure S2). On the other hand, there was a tendency for the pCMV-mtLuc (CGG) [hND4] to show a higher mitochondria gene expression than the other pDNAs. Thus, we focused on improving the mitochondrial carrier encapsulating pCMV-mtLuc (CGG) [hND4]. The high mitochondrial transgene expression in G625A fibroblasts by the mitochondrial transfection of pCMV-mtLuc (CGG) [hND4] via the RP/KALA-MITO-Porter was mainly due to the improvement in mitochondrial transfection where the RP/KALA-MITO-Porter was internalized into the cells more efficiently, resulting larger amounts of the pDNA being delivered to mitochondria than the KALA-MITOPorter.

We also compared the pDNA encapsulation rate, which would be particularly important for mitochondrial transfection, between the KALA-MITO-Porter and the RP/KALA-MITO-Porter, using agarose gel electrophoresis (Figure S7). For electrophoresis, naked pDNA, KALA-MITO-Porter encapsulating pDNA, RP/KALA-MITO-Porter encapsulating pDNA and a Chol-RP solution were treated with $1 \%$ SDS to release the pDNA from the carrier. As a result, in both cases of the KALA-MITO-Porter and the RP/KALA-MITO-Porter, a DNA band was not detected, when SDS was untreated (lanes 4, 6). 
On the other hand, DNA bands were detected at the same position as naked pDNA, when SDS was treated (lanes 3,5$)$. These results indicate that pDNA was efficiently encapsulated in the carriers. In the case of the RP/KALA-MITO-Porter, signals derived from Chol-RP was detected at the same site as was observed for the Chol-RP solution electrophoresis. This result suggests that the excess Chol-RP did not modify the carrier-surface or that Chol-RP that was detached from the carrier during electrophoresis would be detected. Collectively, modifying the KALA-MITO-Porter with PR did not affect the DNA encapsulation efficiency.

The biocompatibility of mitochondrial transfection using the MITO-Porter system is an important issue. Thus, we first evaluated cell viabilities when mitochondria were transfected with various kinds of pDNA using the KALA-MITO-Porter in HeLa cells and G625A fibroblasts (Figure S2). No difference in cell viabilities was found among the pDNA types in both HeLa cells and G625A fibroblasts. Unfortunately, the viabilities of HeLa cells that had been transfected with the KALA-MITO-Porter were decreased to $50 \%$ (Figure S2A). Meanwhile, it was confirmed that cell viabilities were not decreased when any types of pDNA were transfected to mitochondria of G625A fibroblasts by KALA-MITO-Porter (Figure S2B). These results indicate that the cytotoxicity of the KALA-MITO-Porter is different, depending on the cell type. These results indicate that it is important to set optimal transfection conditions including the applied dose and incubation time for each cell type being used. Moreover, we investigated the viability of G625A fibroblasts when mitochondrial transfection was performed using the RP/KALAMITO-Porter (Figure S6). Mitochondrial transfection using RP/KALA-MITO-Porter did not result in a decrease in the viability of G625A cells. Furthermore, we measured the levels of biochemical markers in serum after the administration of RP/KALA-MITO-Porter to mice (Table 2). These results provided us with useful information in terms of applying the RP/KALA-MITO-Porter in animals. As a result, no substantial differences were found between the saline administered mice and the carrier administered mice. This result suggests that the MITO-Porter system would be useful tool for an in vivo mitochondrial transfection system in terms of biocompatibility. 
In conclusion, the findings reported herein demonstrate the utility of a new type of mitochondrial DNA vector with a virus promoter (CMV promoter) and the human mitochondrial endogenous gene (hND4) for achieving mitochondrial transgene expression using pCMV-mtLuc (CGG) [ND4]. Moreover, we optimized the mitochondrial transfection of the pDNA into cells from a patient with a mitochondrial disease (G625A fibroblasts) using the MITO-Porter system, and succeeded in achieving efficient mitochondrial transgene expression by mitochondrial transfection using the RP/KALA-MITO-Porter. Our findings show that this mitochondrial transgene expression system would be a useful tool for mitochondrial gene therapy. In the future, we plan to pursue research into the clinical use such systems for treating patients with mitochondrial diseases. To achieve an innovative approach, it is necessary to add tissue targeting ability in vivo to the MITO-Porter system. Studies directed at this aspect of the process are currently underway. 


\section{ASSOCIATED CONTENT}

\section{Supporting Information}

Supporting Information includes Supplementary Figure (Figures S1-S4), Supplementary Table (Table S1) and Supplementary Vector sequences (Sequences S1-S7).

\section{ACKNOWLEDGMENT}

This work was supported, in part by, a Grant-in-Aid for Scientific Research (B) [grant 26282131 to Y.Y.] and a Grant-in-Aid for Challenging Exploratory Research [grant 25560219 to Y.Y.] from the Ministry of Education, Culture, Sports, Science and Technology, the Japanese Government (MEXT), and the Platform Project for Supporting in Drug Discovery and Life Science Research (Platform for Drug Discovery, Informatics, and Structural Life Science) from Japan Agency for Medical Research and development (AMED). G625A fibroblast cells were kindly supplied by Dr. A. Sudo (nire-no-kai Children's Clinic, Hokkaido, Japan). We also thank Dr. Milton Feather for his helpful advice in writing the manuscript. 
TABLE

Table 1. Sequence of the promoter in pCMV-mtLuc (CGG), pSV40-mtLuc (CGG), pRSV-mtLuc (CGG) and pT7-mtLuc (CGG)

\section{Promoter X}

\section{Sequence}

attaatagtaatcaattacggggtcattagttcatagcccatatatggagttccgcgttacataacttacggtaaatggeccgect ggctgaccgcccaacgaccccecccattgacgtcaataatgacgtatgttcccatagtaacgccaatagggactttccattg acgtcaatgggtggagtatttacggtaaactgcccacttggcagtacatcaagtgtatcatatgccaagtccgcccctattga

CMV cgtcaatgacggtaaatggecegectggcattatgeccagtacatgaccttacgggactttcctacttggcagtacatctacgt attagtcatcgctattaccatgctgatgeggttttggcagtacaccaatgggcgtggatagcggtttgactcacggggatttcc aagtctccaccccattgacgtcaatgggagtttgttttggcaccaaaatcaacgggactttccaaaatgtcgtaataacccegc cccgttgacgcaaatgggcggtaggcgtgtacggtgggaggtctatataagcagacgtcgtttagtgaacc

\begin{tabular}{|c|c|}
\hline SV40 & 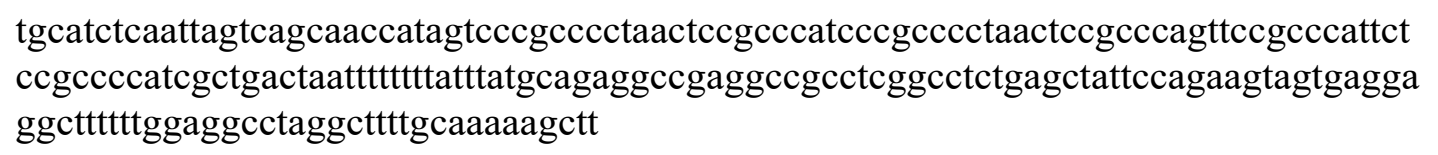 \\
\hline RSV & 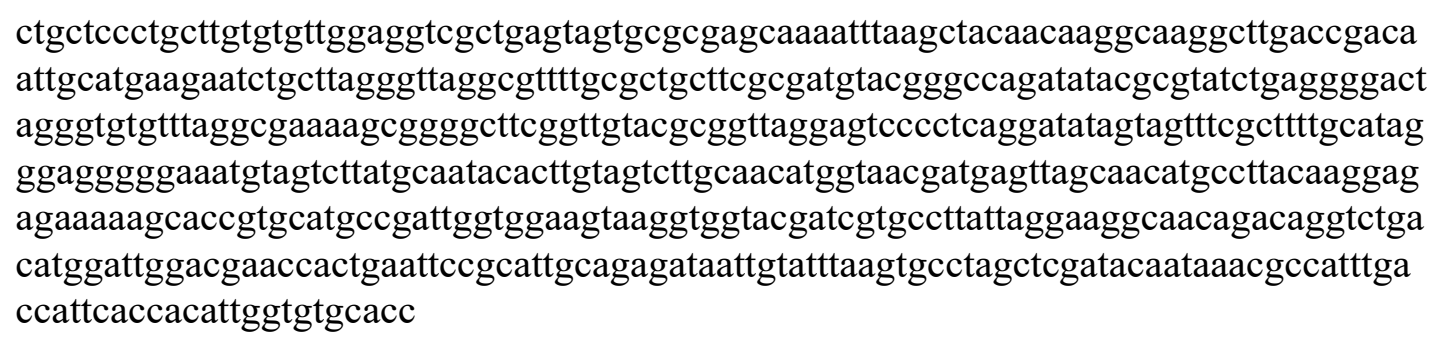 \\
\hline T7 & taatacgactcactatagg \\
\hline
\end{tabular}


Table 2. Measurement of biochemical marker levels in serum after administration of carriers

\begin{tabular}{lccccccccc}
\hline & TP & ALB & BUN & CRE & AST & ALT & LDH & AMY & T-BIL \\
& $(\mathrm{g} / \mathrm{dL})$ & $(\mathrm{g} / \mathrm{dL})$ & $(\mathrm{mg} / \mathrm{dL})$ & $(\mathrm{mg} / \mathrm{dL})$ & $(\mathrm{IU} / \mathrm{L})$ & $(\mathrm{IU} / \mathrm{L})$ & $(\mathrm{IU} / \mathrm{L})$ & $(\mathrm{IU} / \mathrm{L})$ & $(\mathrm{mg} / \mathrm{dL})$ \\
\hline HEPES buffer & 4.6 & 3.0 & 21.2 & 0.13 & 125 & 39.7 & 679 & 2750 & 0.02 \\
Naked pDNA & 4.9 & 3.1 & 25.6 & 0.16 & 150 & 45.3 & 710 & 3056 & 0.05 \\
KALA-MITO-Porter & 4.7 & 3.0 & 24.2 & 0.13 & 110 & 49.0 & 629 & 2903 & 0.04 \\
RP/KALA-MITO-Porter 4.7 & 2.9 & 25.7 & 0.13 & 193 & 40.0 & 676 & 2609 & 0.04 \\
\hline
\end{tabular}

Biochemical marker levels in serum obtained from mice that had been administered the HEPES buffer, naked pCMV-mtLuc (CGG) [hND4], KALA-MITO-Porter encapsulating the pDNA and RP/KALAMITO-Porter encapsulating the pDNA. TP, total protein; ALB, albumin; BUN, blood urea nitrogen; CRE, creatinine; AST, aspartate aminotransferase; ALT, alanine aminotransferase; LDH, lactate dehydrogenase; AMY, amylase; T-BIL, total bilirubin. Data denote the mean $(n=3-4)$. 
Figure 1. Schematic illustration of mitochondrial gene delivery using the MITO-Porter system and mitochondrial gene expression. The MITO-Porter is internalized by cells, and the carrier escapes from the endosome into the cytosol. The carrier then delivers pDNA to mitochondria via membrane fusion. Finally, the pDNA was transcribed to mRNA to produce a protein via translation inside the mitochondrion.

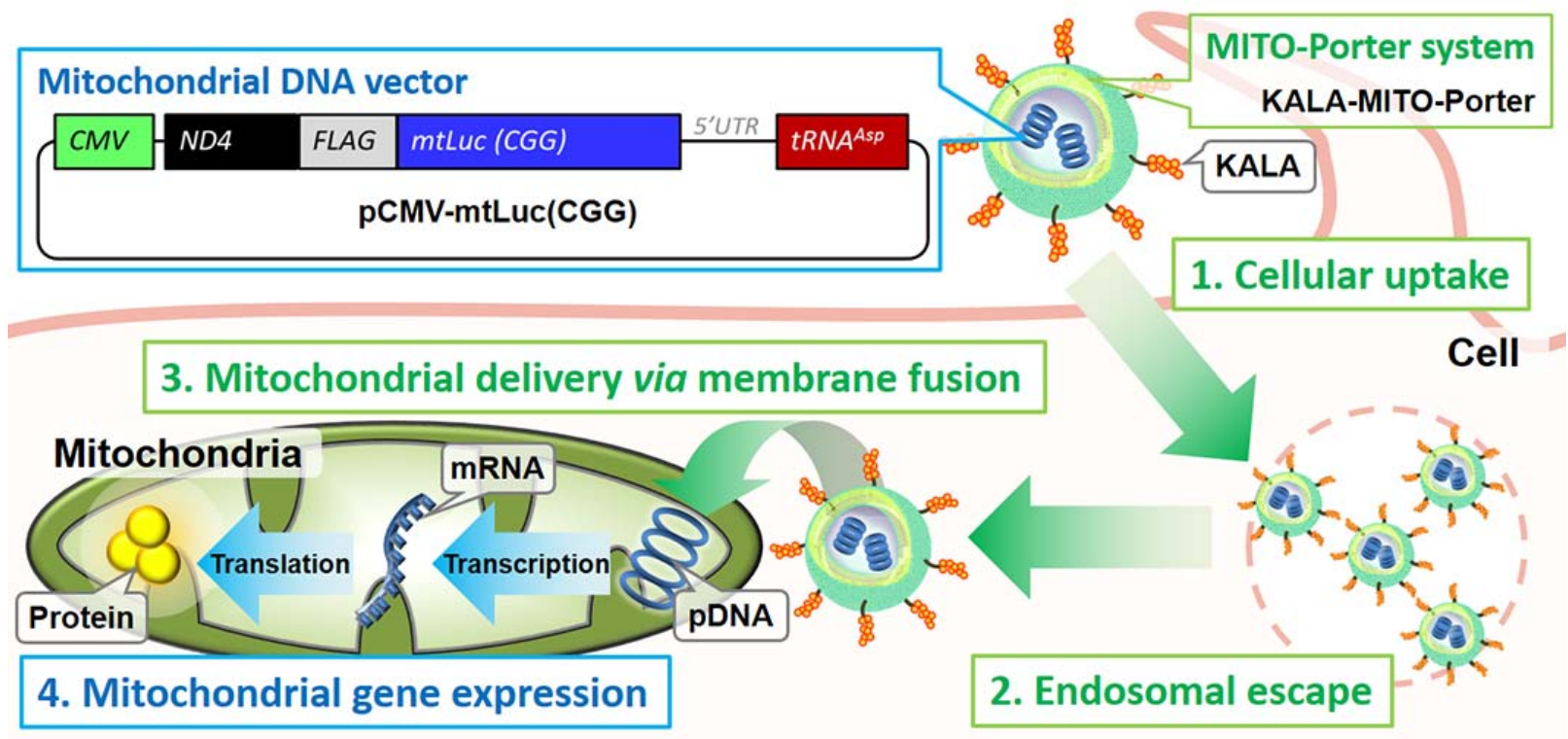


Figure 2. Design of the pDNA vectors used in this study. The designs of pDNAs with different promoter including pCMV-mtLuc (CGG), pSV40-mtLuc (CGG), pRSV-mtLuc (CGG) and pT7-mtLuc (CGG) are shown (A). The pDNAs contain the promoter (CMV, SV40, RSV or T7 promoter), the ND4 gene derived from mouse mtDNA, the mtLuc (CGG) gene that codes mitochondrial Nluc luciferase and tRNA ${ }^{\text {Asp }}$ with the 5'UTR. The pCMV-mtLuc (CGG) [hND4] (B) is different from pCMV-mtLuc (CGG) in terms of containing the $h N D 4$ gene derived from human mtDNA. The pCMV-mtLuc (CGG) [-ND4] (C) is deleted the region of ND4 gene from pCMV-mtLuc (CGG). The pCMV-mtLuc (TAG) (D) contains the mitochondrial/universal stop codon (TAG) in Nluc luciferase gene.

A Structure of pCMV-mtLuc (CGG), pSV40-mtLuc (CGG), pRSV-mtLuc (CGG), pT7-mtLuc (CGG)

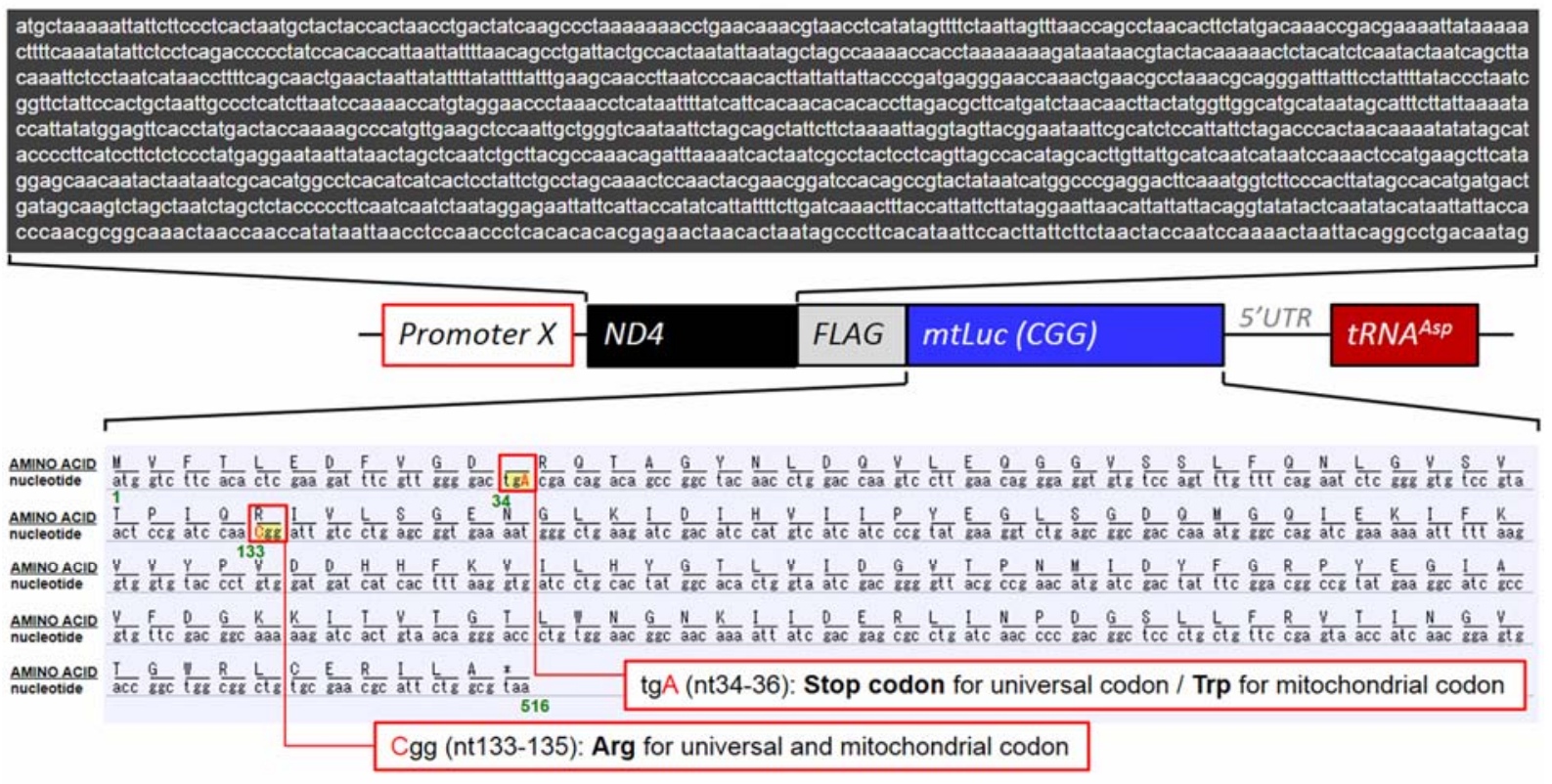

B pCMV-mtLuc (CGG) [hND4]
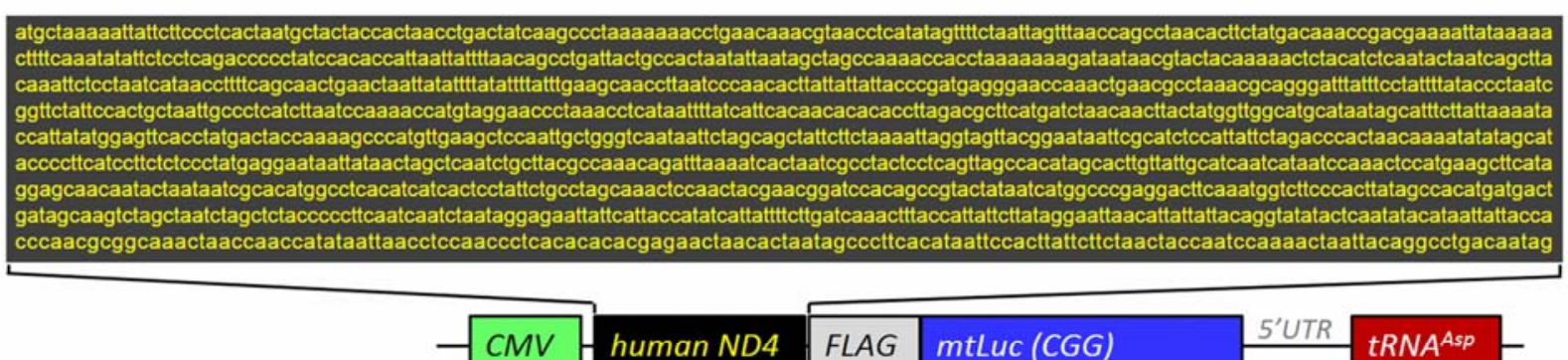

human ND4

\begin{tabular}{|l|l|l|l|l}
\hline FLAG & mtLuc (CGG) \\
\hline
\end{tabular}

S'UTR

tRNA Asp

C pCMV-mtLuc (CGG) [-ND4]

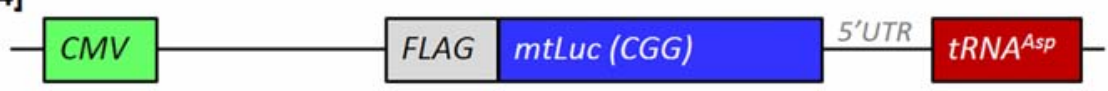

D pCMV-mtLuc (TAG)

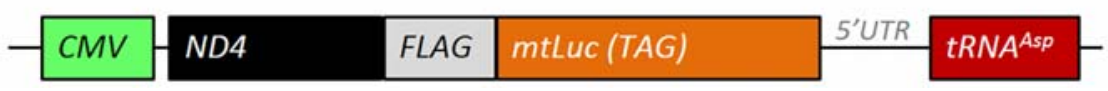


Figure 3. Evaluation of the transgene expression of the pDNA vector using hydrodynamic injection. (A) A $100 \mu \mathrm{g}$ portion of pCMV-mtLuc (CGG), pSV40-mtLuc (CGG), pRSV-mtLuc (CGG), pT7-mtLuc (CGG) were administered to mice via the tail vein by HTV injection. The livers were harvested at $6 \mathrm{hr}$ postinjection and the Nluc luciferase activities were measured. (B) A $100 \mu \mathrm{g}$ of pCMV-mtLuc (CGG), pCMV-mtLuc (CGG)[hND4], pCMV-mtLuc (CGG)[-ND4], were administered via the tail vein of mice via HTV injection, and the livers were harvested at $6 \mathrm{hr}$ postinjection and the Nluc luciferase activities were measured. Bars represent the means \pm SD. ( $n=3)$. **Significant differences (vs pCMV-mtLuc(CGG)) were calculated by one-way ANOVA, followed by bonfferoni test $(\mathrm{p}<0.01)$.

A

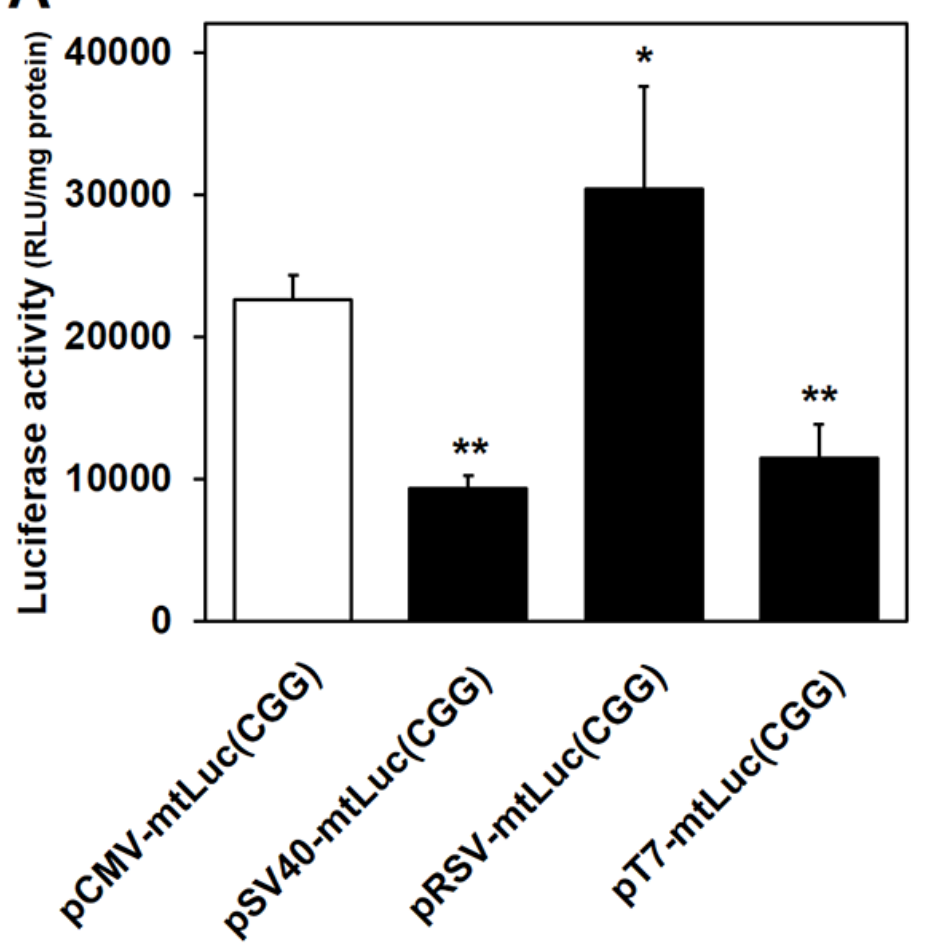

B

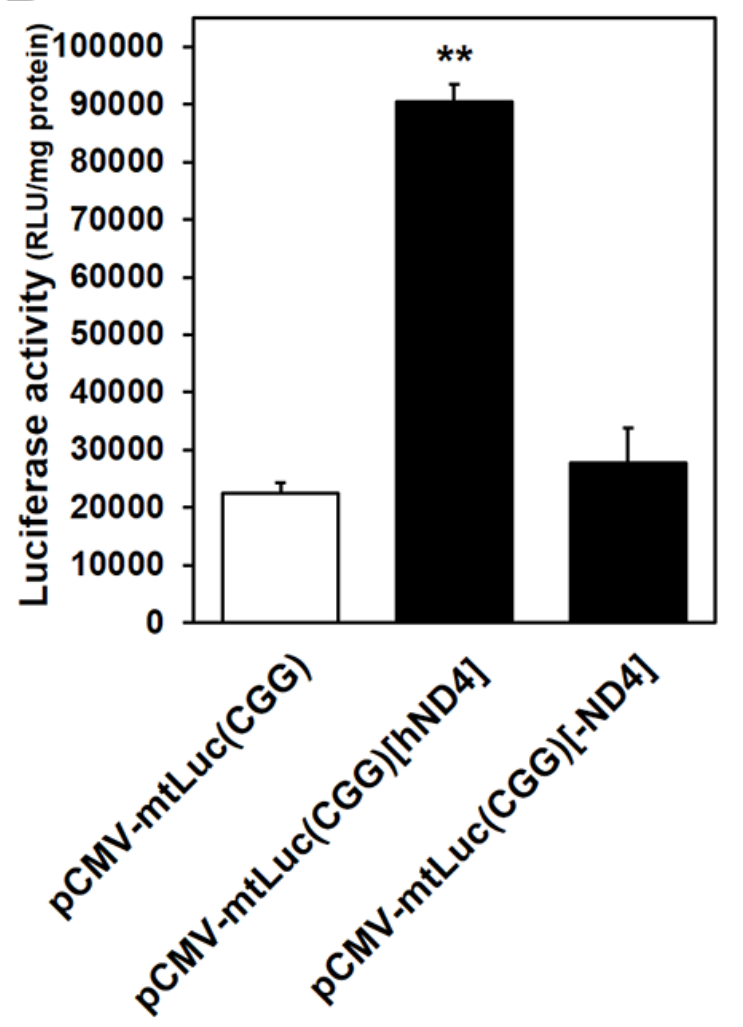


Figure 4. Investigation of mitochondrial gene expression using the KALA-MITO-Porter. (A) Evaluation of transgene expression in HeLa cells. A $0.4 \mu \mathrm{g}$ of pCMV- mtLuc (CGG), pSV40-mtLuc (CGG), pRSVmtLuc (CGG), pT7-mtLuc (CGG), pCMV- mtLuc (CGG) [hND4] were transfected to HeLa cells using the KALA-MITO-Porter. After $24 \mathrm{hr}$ transfection, the Nluc luciferase activities were measured. Bars represent the mean \pm SD. ( $n=3$ ). Significant differences (vs pCMV-mtLuc (CGG)) were calculated by oneway ANOVA, followed by bonfferoni test $(* * \mathrm{p}<0.01)$. (B) Evaluation of transgene expression in G625A fibroblasts. A $0.4 \mu \mathrm{g}$ portion of pCMV-mtLuc (CGG) [hND4] was transfected to G625A fibroblasts using the KALA-MITO-Porter. After $24 \mathrm{hr}$ transfection, the Nluc luciferase activities were measured. Bars represent the mean \pm SD. ( $n=3$ ). No significant difference (N.S.) indicates the lack of a statistically significant difference $(\mathrm{p}>0.05$ by t-test).
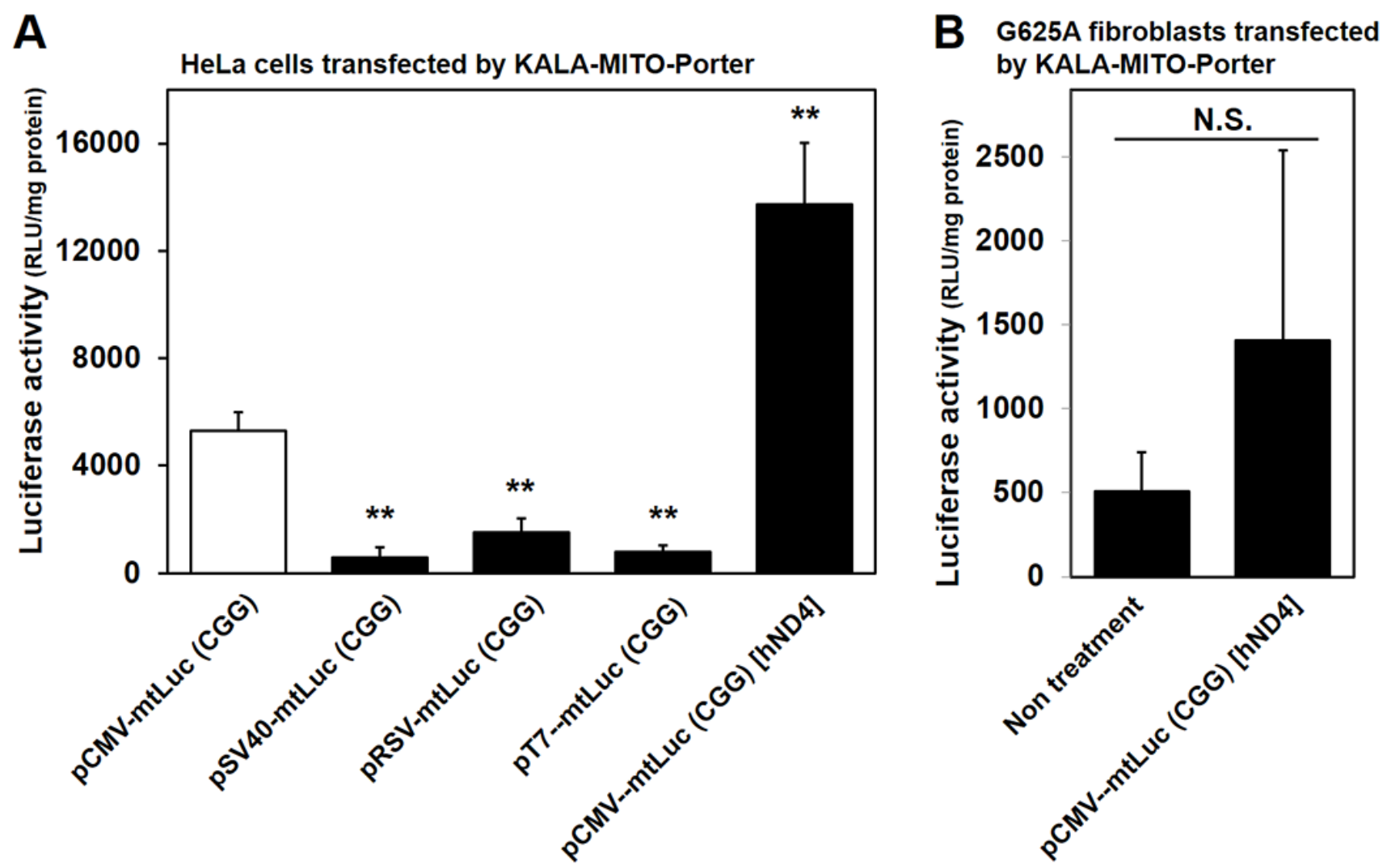
Figure 5. Evaluating the cellular uptake of Cy-5 labeled pDNA transfected by the RP/KALA-MITOPorter in G625A fibroblasts by flow cytometry analysis. The cellular uptake values for the KALA-MITOPorter modified with various ratios of RP (closed columns) and RP-unmodified ones (open columns) are summarized. Data are represented as the mean \pm S.D $(n=3)$. Significant differences (vs RP-unmodified KALA-MITO-Porter) were calculated by one-way ANOVA, followed by bonfferoni test $(* * \mathrm{p}<0.01)$.

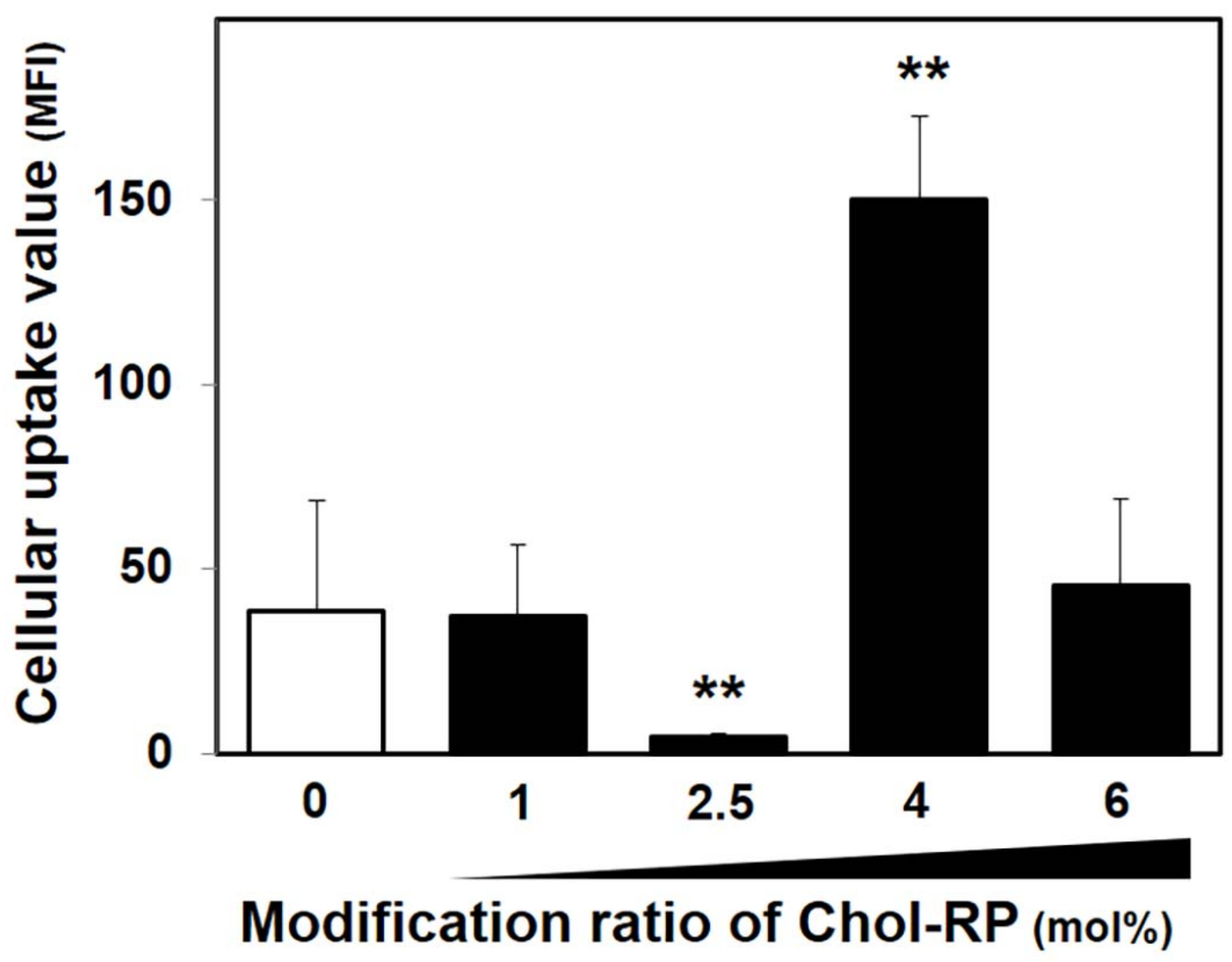


Figure 6. Comparison of mitochondrial transfection between the KALA-MITO-Porter and the RP/KALA-MITO-Porter. (A) Intracellular observation using CLSM after pDNA transfection by KALAMITO-Porter (a) and RP/KALA-MITO-Porter (b). Cy-5 labeled pCMV-mtLuc (CGG) (pseudo green color) is seen to colocalize with red-stained mitochondria in G625A fibroblasts, observed as yellow signals in the merged image. Scale bars; $30 \mu \mathrm{m}$. (For interpretation of the references to colour in this figure legend, the reader is referred to the web version of this article.) (B) Evaluation the transgene expression of pCMV-mtLuc (CGG) [hND4]. G625A fibroblasts were transfected with $0.4 \mu \mathrm{g}$ of pCMVmtLuc (CGG) [hND4] or pCMV- mtLuc (TAG) using the KALA-MITO-Porter, the RP/KALA-MITOPorter and the absence of a carrier. Nluc luciferase activities were measured at $24 \mathrm{hr}$ after transfection. Bars represent the mean \pm SD. $(n=3)$. Two-way ANOVA analysis was performed to compare the effect of two factors that are "pDNA type" and "carrier type". Because there was significant interaction between 2 factors, simple main effect test also performed. $* * *$ significant differences $(\mathrm{p}<0.001$ by simple main effect test, followed by Bonferroni correction).

A

(a) KALA-MITO-Porter

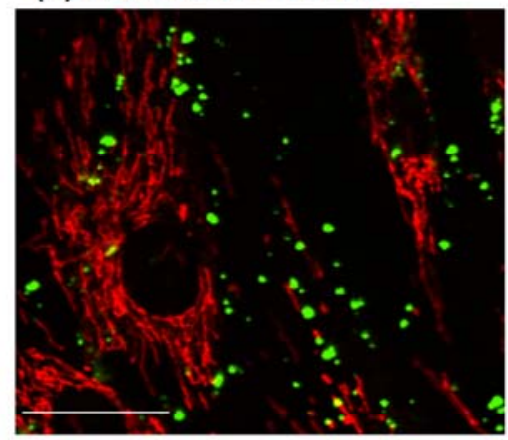

(b) RP/KALA-MITO-Porter

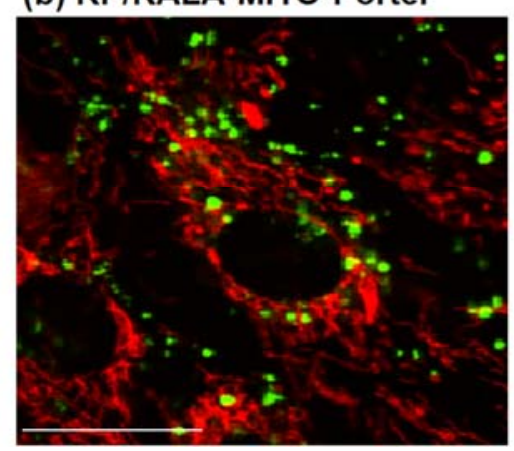

B

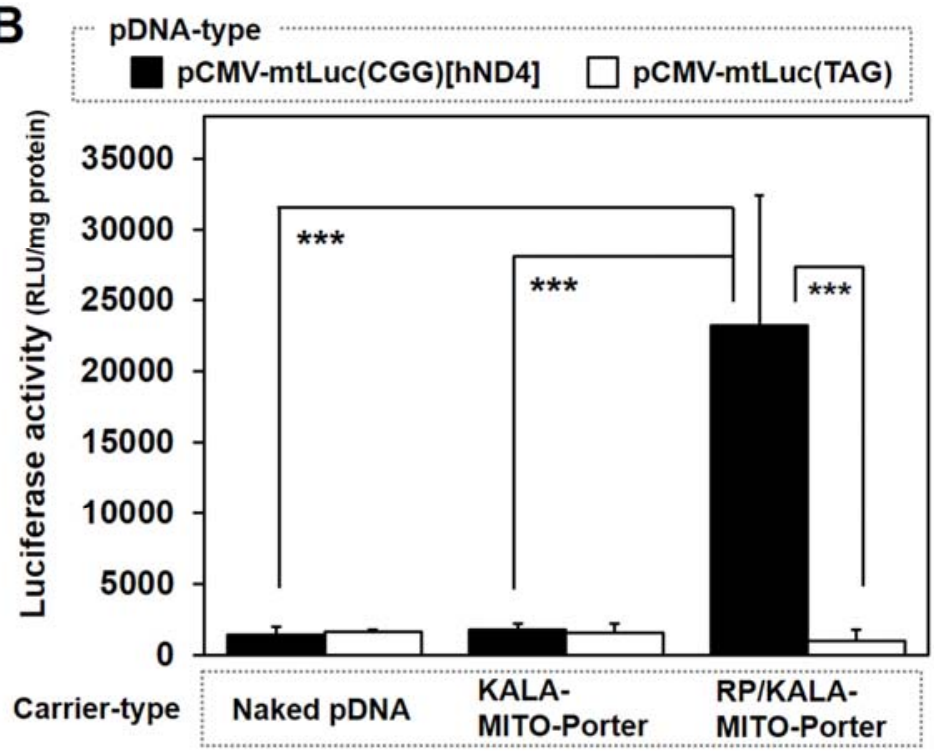

Two way ANOVA analysis result

\begin{tabular}{lc}
\hline Factors & P-value by two way ANOVA \\
\hline pDNA-type & $<0.001$ \\
Carrier-type & $<0.001$ \\
Interaction between two factors & $<0.001$ \\
\hline
\end{tabular}




\section{REFERENCES.}

[1] S. DiMauro, M. Hirano, E.A. Schon, Approaches to the treatment of mitochondrial diseases, Muscle Nerve, 34 (2006) 265-283.

[2] L.J. Martin, Mitochondriopathy in Parkinson disease and amyotrophic lateral sclerosis, J Neuropathol Exp Neurol, 65 (2006) 1103-1110.

[3] E. Sarzi, M.D. Brown, S. Lebon, D. Chretien, A. Munnich, A. Rotig, V. Procaccio, A novel recurrent mitochondrial DNA mutation in ND3 gene is associated with isolated complex I deficiency causing Leigh syndrome and dystonia, Am J Med Genet A, 143A (2007) 33-41.

[4] Y. Goto, I. Nonaka, S. Horai, A mutation in the tRNA(Leu)(UUR) gene associated with the MELAS subgroup of mitochondrial encephalomyopathies, Nature, 348 (1990) 651-653.

[5] Y. Yamada, T. Ishikawa, H. Harashima, Validation of the use of an artificial mitochondrial reporter DNA vector containing a Cytomegalovirus promoter for mitochondrial transgene expression, Biomaterials, 136 (2017) 56-66.

[6] Y. Yamada, H. Akita, H. Kamiya, K. Kogure, T. Yamamoto, Y. Shinohara, K. Yamashita, H. Kobayashi, H. Kikuchi, H. Harashima, MITO-Porter: A liposome-based carrier system for delivery of macromolecules into mitochondria via membrane fusion, Biochimica et biophysica acta, 1778 (2008) 423-432.

[7] Y. Yamada, H. Harashima, MITO-Porter for Mitochondrial Delivery and Mitochondrial Functional Analysis, Handb Exp Pharmacol, 240 (2017) 457-472.

[8] T.B. Wyman, F. Nicol, O. Zelphati, P.V. Scaria, C. Plank, F.C. Szoka, Design, synthesis, and characterization of a cationic peptide that binds to nucleic acids and permeabilizes bilayers, Biochemistry, 36 (1997) 3008-3017.

[9] A. Sudo, N. Takeichi, K. Hosoki, S. Saitoh, Successful cochlear implantation in a patient with mitochondrial hearing loss and m.625G $>$ A transition, J Laryngol Otol, 125 (2011) 1282-1285.

[10] Y. Yamada, R. Furukawa, H. Harashima, A Dual-Ligand Liposomal System Composed of a CellPenetrating Peptide and a Mitochondrial RNA Aptamer Synergistically Facilitates Cellular Uptake and Mitochondrial Targeting, J Pharm Sci, 105 (2016) 1705-1713.

[11] S.M. Shaheen, H. Akita, T. Nakamura, S. Takayama, S. Futaki, A. Yamashita, R. Katoono, N. Yui, H. Harashima, KALA-modified multi-layered nanoparticles as gene carriers for MHC class-I mediated antigen presentation for a DNA vaccine, Biomaterials, 32 (2011) 6342-6350.

[12] F. Liu, Y. Song, D. Liu, Hydrodynamics-based transfection in animals by systemic administration of plasmid DNA, Gene Ther, 6 (1999) 1258-1266.

[13] Y. Yasuzaki, Y. Yamada, T. Kanefuji, H. Harashima, Localization of exogenous DNA to mitochondria in skeletal muscle following hydrodynamic limb vein injection, J Control Release, 172 (2013) 805-811.

[14] Y. Yasuzaki, Y. Yamada, T. Ishikawa, H. Harashima, Validation of Mitochondrial Gene Delivery in Liver and Skeletal Muscle via Hydrodynamic Injection Using an Artificial Mitochondrial Reporter DNA Vector, Mol Pharm, 12 (2015) 4311-4320.

[15] M. Boshart, F. Weber, G. Jahn, K. Dorschhasler, B. Fleckenstein, W. Schaffner, A Very Strong Enhancer Is Located Upstream of an Immediate Early Gene of Human Cytomegalo-Virus, Cell, 41 (1985) 521-530.

[16] A.A. Zarrin, L. Malkin, I. Fong, K.D. Luk, A. Ghose, N.L. Berinstein, Comparison of CMV, RSV, SV40 viral and Vlambdal cellular promoters in B and $\mathrm{T}$ lymphoid and non-lymphoid cell lines, Biochimica et biophysica acta, 1446 (1999) 135-139.

[17] D. Nayak, Q. Guo, R. Sousa, A promoter recognition mechanism common to yeast mitochondrial and phage t7 RNA polymerases, J Biol Chem, 284 (2009) 13641-13647.

[18] T.E. Shutt, M.W. Gray, Bacteriophage origins of mitochondrial replication and transcription proteins, Trends Genet, 22 (2006) 90-95. 
[19] T. Suda, D. Liu, Hydrodynamic gene delivery: its principles and applications, Mol Ther, 15 (2007) 2063-2069.

[20] N. Kobayashi, M. Nishikawa, Y. Takakura, The hydrodynamics-based procedure for controlling the pharmacokinetics of gene medicines at whole body, organ and cellular levels, Adv Drug Deliv Rev, 57 (2005) 713-731.

[21] B. Bonamassa, L. Hai, D. Liu, Hydrodynamic gene delivery and its applications in pharmaceutical research, Pharmaceutical research, 28 (2011) 694-701.

[22] H.M. Ellerby, W. Arap, L.M. Ellerby, R. Kain, R. Andrusiak, G. Del Rio, S. Krajewski, C.R. Lombardo, R. Rao, E. Ruoslahti, D.E. Bredesen, R. Pasqualini, Anti-cancer activity of targeted proapoptotic peptides, Nature medicine, 5 (1999) 1032-1038.

[23] X.C. Ma, X.B. Wang, M. Zhou, H. Fei, A Mitochondria-Targeting Gold-Peptide Nanoassembly for Enhanced Cancer-Cell Killing, Adv Healthc Mater, 2 (2013) 1638-1643.

[24] Y. Yamada, R. Furukawa, Y. Yasuzaki, H. Harashima, Dual function MITO-Porter, a nano carrier integrating both efficient cytoplasmic delivery and mitochondrial macromolecule delivery, Mol Ther, 19 (2011) 1449-1456.

[25] K. Kajimoto, Y. Sato, T. Nakamura, Y. Yamada, H. Harashima, Multifunctional envelope-type nano device for controlled intracellular trafficking and selective targeting in vivo, J Control Release, 190C (2014) 593-606. 


\section{Supplementary Figures}

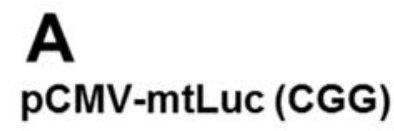

attaatagtaatcaattacggggtcattagttcatagcccatatatggagttccgcgttacataacttacggtaaatggcccgcctggctgaccgcccaacgacccccgcccatt gacgtcaataatgacgtatgttcccatagtaacgccaatagggacttccattgacgtcaatgggtggagtatttacggtaaactgcccacttggcagtacatcaagtgtatcata tgccaagtccgcccctattgacgtcaatgacggtaaatggcccgcctggcattatgcccagtacatgaccttacgggactttcctacttggcagtacatctacgtattagtcatc gctattaccatgctgatgcggtttggcagtacaccaatgggcgtggatagcggtttgactcacggggatttccaagtctccaccccattgacgtcaatgggagtttgtttggcac caaaatcaacgggacttccaaaatgtcgtaataaccccgccccgttgacgcaaatgggcggtaggcgtgtacggtgggaggtctatataagcagacgtcgtttagtgaacc 4
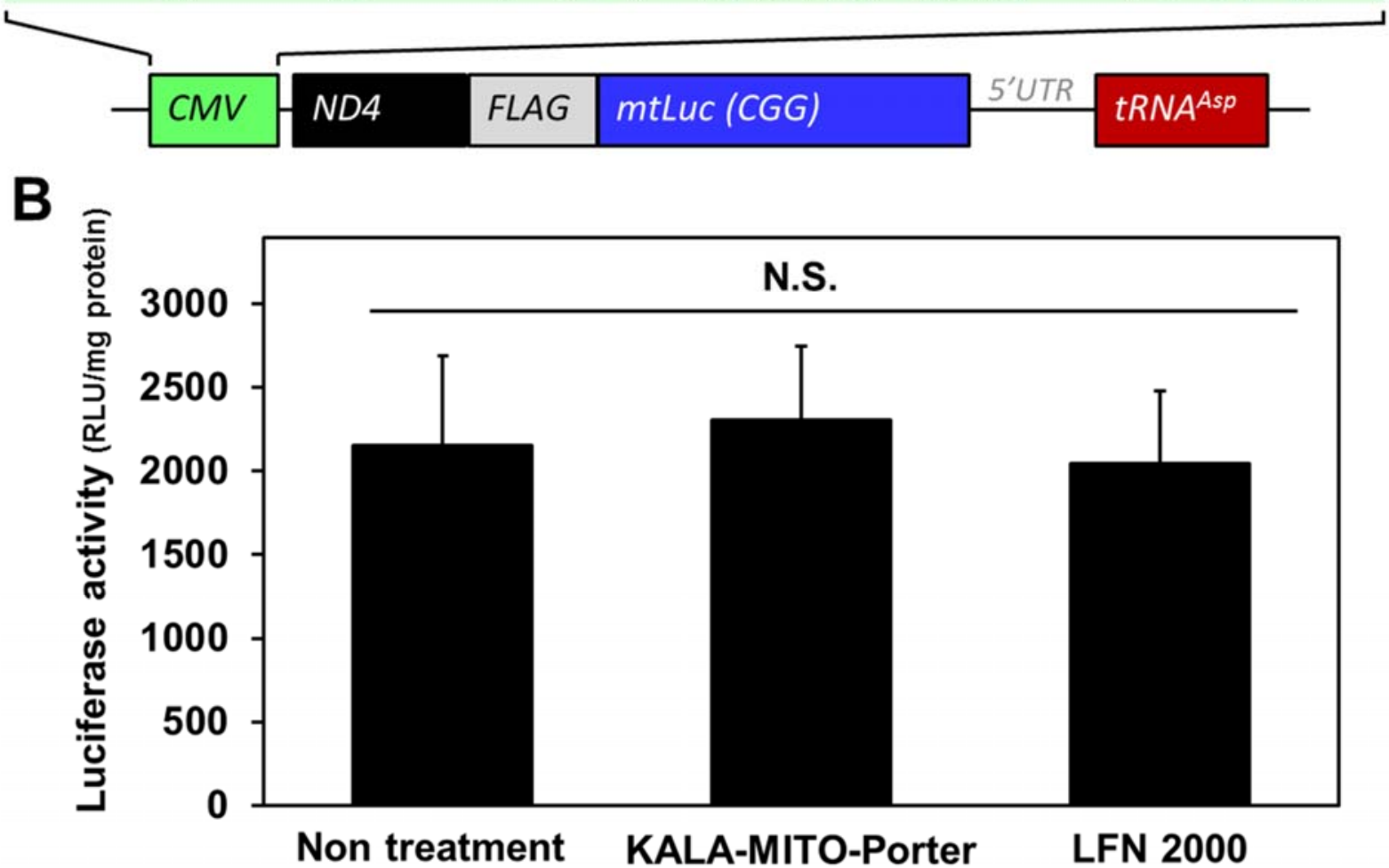

Figure S1 Evaluation of the transgene expression of pCMV-mtLuc (CGG) in G625A fibroblasts. Design of pCMV-mtLuc (CGG) (A). The pDNA contains the CMV promoter, the mtLuc (CGG) gene that codes for mitochondrial Nluc luciferase and tRNA ${ }^{\text {Asp }}$ with the 5 'UTR. Sequence information is shown in Supplementary Vector sequences (Sequence S1). Evaluation of mitochondrial transfection activity (B). A $0.4 \mu \mathrm{g}$ of pCMV-mtLuc (CGG) was transfected to G625A fibroblasts using KALA-MITO-Porter and LFN 2000. Nluc luciferase activities were measured after a $24 \mathrm{hr}$ period of transfection. Bars represent the means \pm SD. $(n=3)$. No significant difference (N.S.) indicates the lack of a statistically significant difference ( $p>0.05$ by one-way ANOVA). 
A

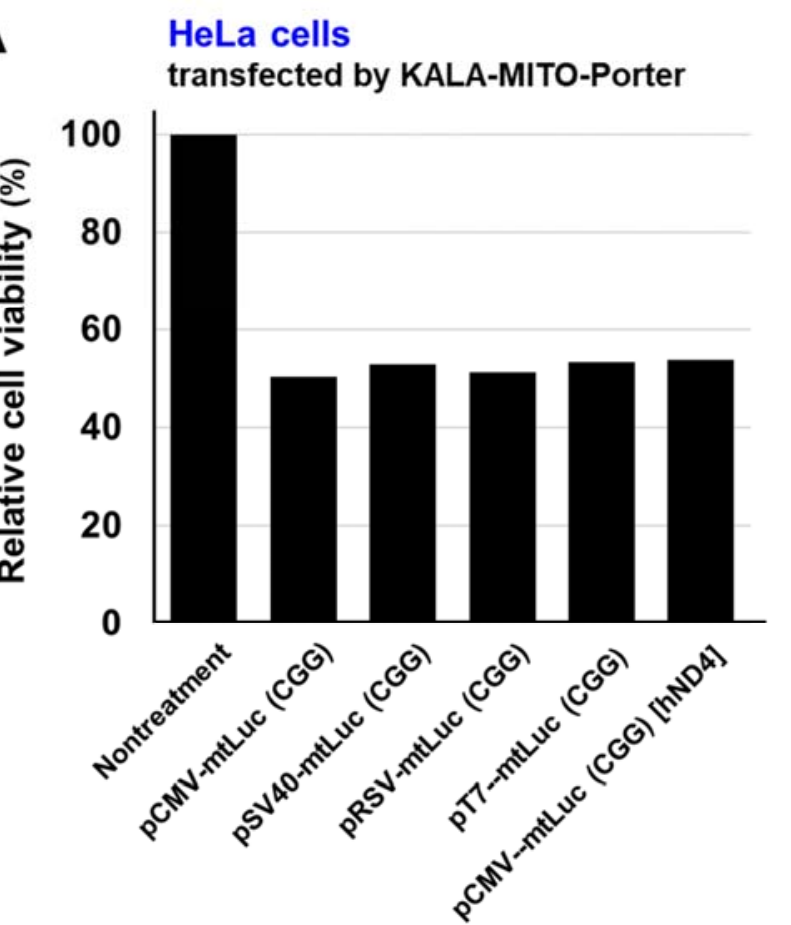

B
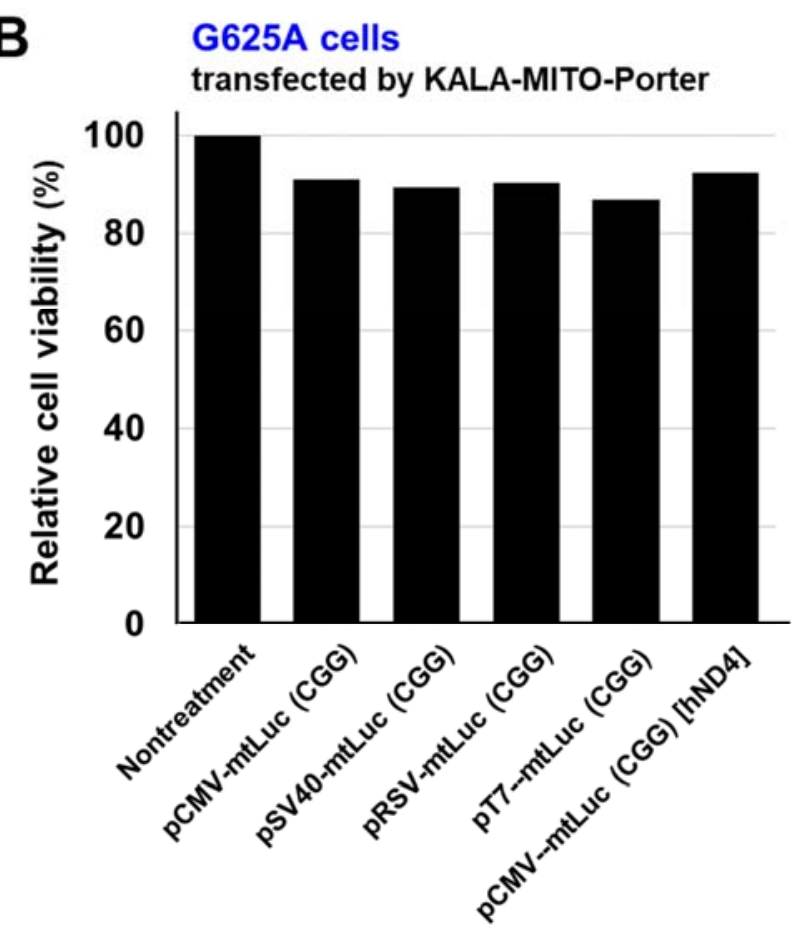

Figure S2 Cell viability for the mitochondrial transfection of various types of pDNA using the KALAMITO-Porter. Samples (0.4 $\mu \mathrm{g})$ of pCMV- mtLuc (CGG), pSV40-mtLuc (CGG), pRSV-mtLuc (CGG), pT7-mtLuc (CGG) or pCMV- mtLuc (CGG) [hND4] were transfected to HeLa cells (A) or G625A fibroblasts (B) using the KALA-MITO-Porter. At $24 \mathrm{hr}$ after transfection, the cells were solubilized with reporter lysis buffer, and the relative cell viability estimated, as follows: Relative cell viability $(\%)=\mathrm{P}_{\mathrm{S}} / \mathrm{P}_{U}$ $\mathrm{x}$ 100; where $\mathrm{P}_{\mathrm{S}}$ and $\mathrm{P}_{\mathrm{U}}$ represent the protein concentrations for treated and untreated cells with samples, respectively. Protein concentrations were determined using a BCA protein assay kit. Data are represented as the mean $(\mathrm{n}=2)$. 


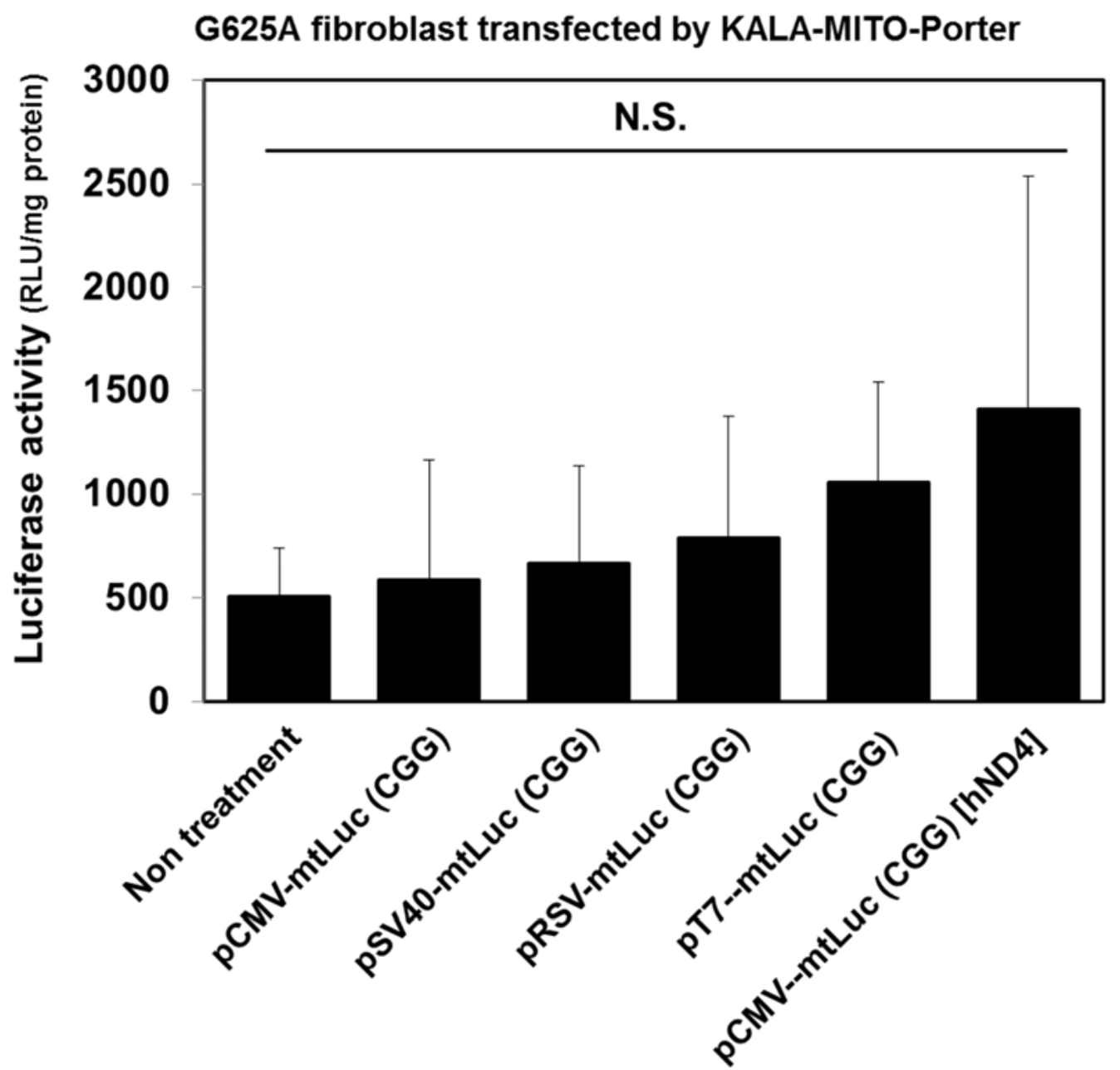

Figure S3 Evaluation of the transgene expression of pDNA vectors in G625A fibroblasts. A $0.4 \mu \mathrm{g}$ amount of pCMV-mtLuc (CGG), pSV40-mtLuc (CGG), pRSV-mtLuc (CGG), pT7-mtLuc (CGG), pCMV- mtLuc (CGG) [hND4] were transfected to G625A fibroblasts using the KALA-MITO-Porter. Nluc luciferase activities were measured after a $24 \mathrm{hr}$ period of transfection. Bars represent the means \pm SD. ( $\mathrm{n}=3$ ). No significant difference (N.S.) indicates the lack of a statistically significant difference ( $p>0.05$ by oneway ANOVA). 


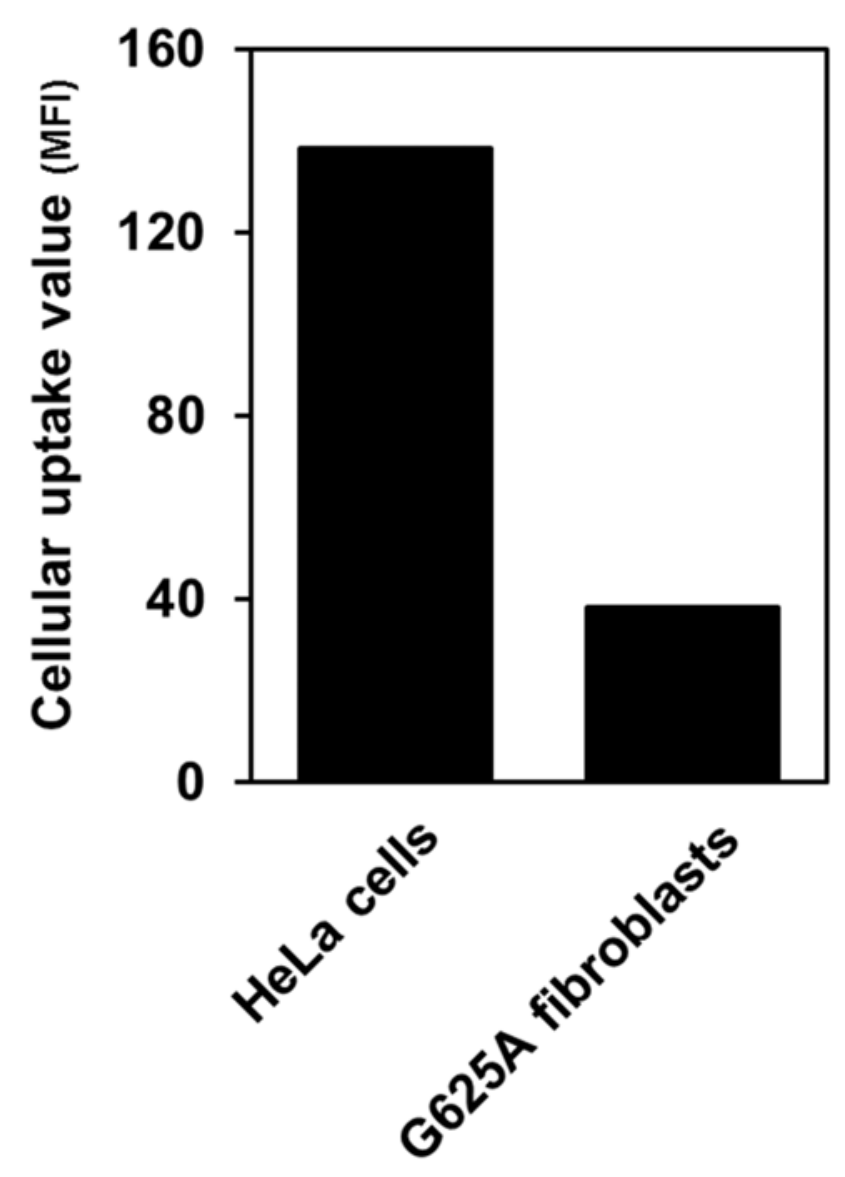

Figure S4 Evaluation of the cellular uptake of Cy-5 labeled pDNA transfected by the KALA-MITOPorter by flow cytometry analysis. The cellular uptake is expressed as the MFI. Data are represented as the mean \pm S.D $(n=1-3)$. 


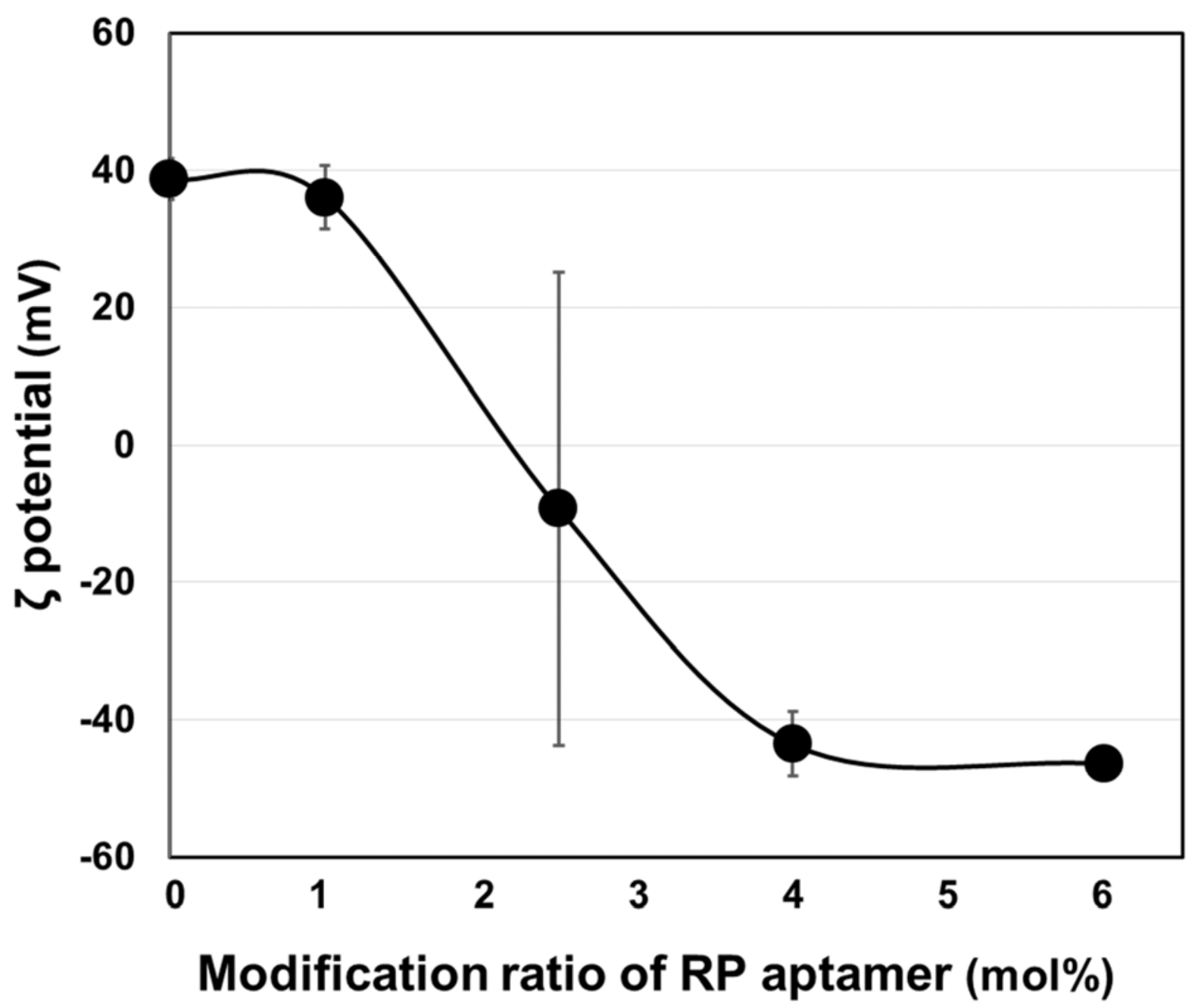

Figure S5 Relationship between the modification ratios of RP aptamer and $\zeta$-potentials of KALA-MITOPorter. KALA-MITO-Porter was modified with RP aptamer at a series of modification ratios (mol \%). Their $\zeta$-potentials are summarized. Data are represented as the mean \pm S.D $(n=3)$. 


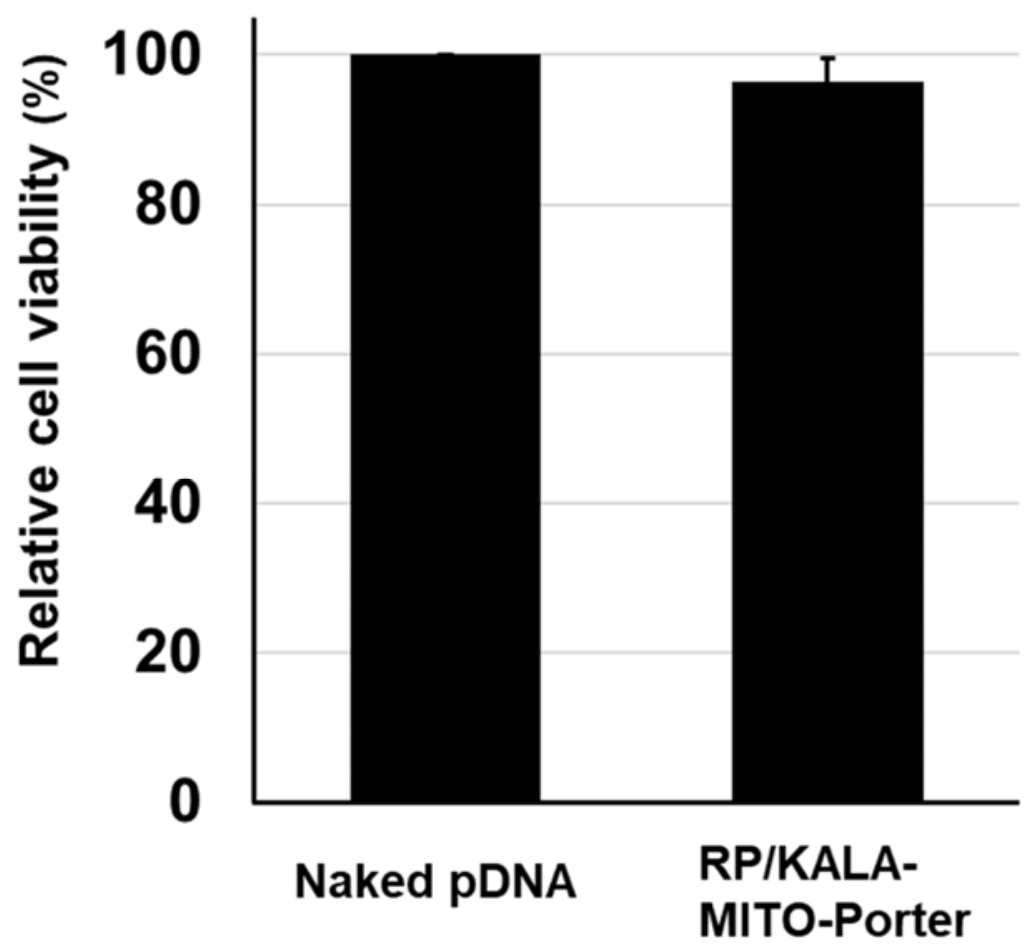

Figure S6 Effect of mitochondrial transfection using the RP/KALA-MITO-Porter on the cell viability of G625A fibroblasts. G625A fibroblasts were transfected with $0.4 \mu \mathrm{g}$ of pCMV-mtLuc (CGG) [hND4] with or without the RP/KALA-MITO-Porter. At $24 \mathrm{hr}$ after transfection, the cells were solubilized with reporter lysis buffer, and the resulting cell lysate was used to estimate the relative cell viability as follows: Relative cell viability $(\%)=\mathrm{P}_{\text {with }} / \mathrm{P}_{\text {without }} \mathrm{X} 100$; where $\mathrm{P}_{\text {with }}$ and $\mathrm{P}_{\text {without }}$ represent the protein concentrations for cell transfected pDNA with and without RP/KALA-MITO-Porter, respectively. Protein concentrations were determined using a BCA protein assay kit. Data are represented as the mean \pm S.D $(n=6)$. 


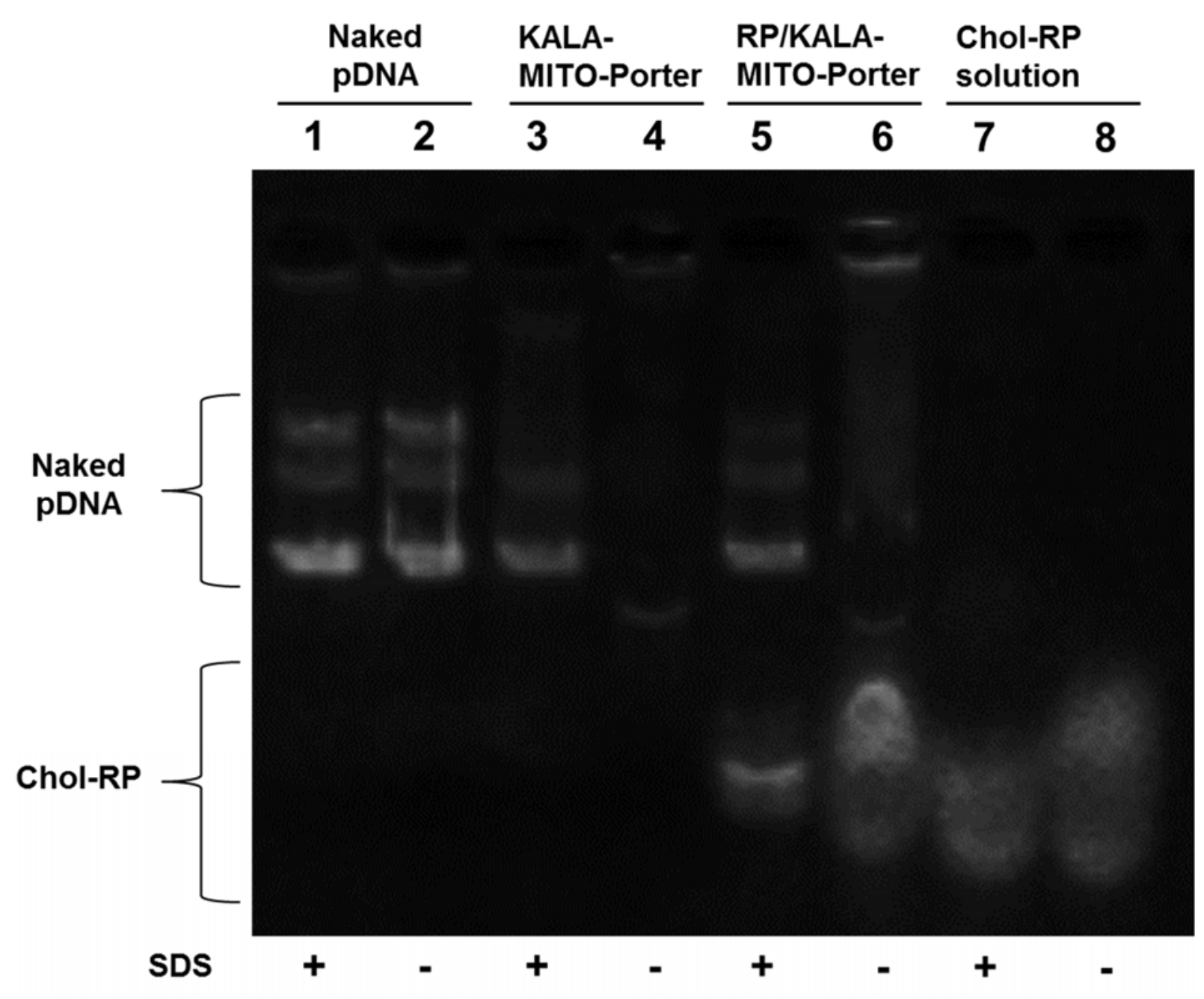

Figure S7 Agarose gel electrophoresis data for the encapsulation of pDNA in the KALA-MITO-Porter and the RP/KALA-MITO-Porter. The samples (naked pDNA, KALA-MITO-Porter encapsulating pDNA, RP/KALA-MITO-Porter encapsulating pDNA and Chol-RP solution) were treated with 1\% SDS to release the pDNA from the carrier. Electrophoresis was performed on $1 \%$ agarose gel at $100 \mathrm{~V}$ for $30 \mathrm{~min}$, and the DNA bands were then visualized by UV after staining with GelRed (Biotium, Hayward, CA, USA). Signals derived from Chol-RP were shown in the lower part of the gel in lanes 5-8. 


\section{Supplementary Table}

Table S1. Positions of point mutations in the Nluc luciferase gene in constructing the artificial mitochondrial reporter DNA vector

\begin{tabular}{lll}
\hline Gene & $\begin{array}{l}\text { Codon } \\
\text { (position) }\end{array}$ & Amino acid encoded by the codon \\
\hline $\begin{array}{l}\text { Nluc } \\
\text { [Wild-type] }\end{array}$ & $\operatorname{tgg}(34-36)$ & Trp for universal and mitochondrial codon \\
& $\operatorname{agg}(133-135)$ & Arg for universal codon / Stop codon for mitochondrial codon \\
\hline mtLuc (CGG) & $\operatorname{tgA}(34-36)$ & Stop codon for universal codon / Trp for mitochondrial codon \\
& Cgg (133-135) & Arg for universal and mitochondrial codon \\
\hline & $\operatorname{tgA}(34-36)$ & Stop codon for universal codon / Trp for mitochondrial codon \\
\hline
\end{tabular}

Positions of point mutation in Nluc luciferase gene are indicated in upper case letters. 


\section{Supplementary Vector sequences}

The DNA vectors were designed by inserting the DNA fragment gene as shown below (Sequences S1S7) into pBluescript SK (-) vector (Stratagene) between the multi cloning site (EcoR I and Sma I sites).

Sequence S1 for pCMV-mtLuc(CGG). The DNA sequence contains CMV promoter [highlighted in green], ND4 gene [highlighted in gray], the sequence corresponding to FLAG [highlighted in yellow], mtLuc (CGG) gene [highlighted in aqua] and tRNA ${ }^{\text {Asp }}$ gene with the 5'UTR [highlighted in pink]. The CMV promoter was derived from pTriEx-3 Neo Vector (Promega, Madison, WI, USA) to bases 1,0211,596. The ND4 gene, tRNA Asp gene with the 5'UTR were derived from mouse mtDNA corresponding to bases 10,168-11,544 and bases 6,873-7,011 (GenBank: JF286601.1), respectively. The mtLuc (CGG) gene was synthesized by inserting the point mutation shown by UPPER CASE letters into Nanoluc luciferase gene of pNL1.1[Nluc] corresponding to bases 100-615 (GenBank: JQ437370.1). We previously reported this sequence information in reference [1].

(5'EcoRI) -

ctgcagattaatagtaatcaattacggggtcattagttcatagcccatatatggagttccgcgttacataacttacggtaaatggecegectggetgaccg cccaacgaccccgeccattgacgtcaataatgacgtatgttcccatagtaacgecaatagggactttccattgacgtcaatgggtggagtatttacggt aaactgcccacttggcagtacatcaagtgtatcatatgccaagtccgeccctattgacgtcaatgacggtaaatggeccgectggcattatgeccagta catgaccttacgggactttcctacttggcagtacatctacgtattagtcatcgctattaccatgctgatgeggtttggcagtacaccaatgggcgtggata gcggtttgactcacggggatttccaagtctccaccccattgacgtcaatgggagtttgttttggcaccaaaatcaacgggactttccaaaatgtcgtaata acccegcccgttgacgcaaatgggcggtaggcgtgtacggtgggaggtctatataagcagacgtcgtttagtgaaccatgctaaaaattattcttccet cactaatgctactaccactaacctgactatcaagccctaaaaaaacctgaacaaacgtaacctcatatagttttctaattagtttaaccagcctaacacttct atgacaaaccgacgaaaattataaaaacttttcaaatatattctcctcagaccccetatccacaccattaattattttaacagcetgattactgecactaatatt aatagctagccaaaaccacctaaaaaaagataataacgtactacaaaaactctacatctcaatactaatcagcttacaaattctcctaatcataaccttttca gcaactgaactaattatattttatattttatttgaagcaaccttaatcccaacacttattattattacccgatgagggaaccaaactgaacgectaaacgcagg gatttatttcctattttataccctaatcggttctattccactgctaattgecetcatcttaatccaaaaccatgtaggaaccctaaacctcataattttatcattcac aacacacaccttagacgcttcatgatctaacaacttactatggttggcatgcataatagcatttcttattaaaataccattatatggagttcacctatgactacc aaaagcccatgttgaagctccaattgctgggtcaataattctagcagctattcttctaaaattaggtagttacggaataattcgcatctccattattctagacc cactaacaaaatatatagcatacccettcatccttctctccetatgaggaataattataactagctcaatctgcttacgccaaacagatttaaaatcactaatc gectactcetcagttagccacatagcacttgttattgcatcaatcataatccaaactccatgaagcttcataggagcaacaatactaataatcgcacatggc ctcacatcatcactcctattctgcctagcaaactccaactacgaacggatccacagccgtactataatcatggeccgaggacttcaaatggtcttcccact tatagccacatgatgactgatagcaagtctagctaatctagctctaccccettcaatcaatctaataggagaattattcattaccatatcattatttcttgatca aactttaccattattcttataggaattaacattattattacaggtatatactcaatatacataattattaccacccaacgeggcaaactaaccaaccatataatta acctccaaccctcacacacacgagaactaacactaatagcccttcacataattccacttattcttctaactaccaatccaaaactaattacaggcctgacaa tagattacaaggatgacgacgataagatggtcttcacactcgaagatttcgttggggactgAcgacagacagecggctacaacctggaccaagtcctt gaacagggaggtgtgtccagtttgtttcagaatctcggggtgtccgtaactccgatccaa Cggattgtcctgagcggtgaaaatgggetgaagatcga catccatgtcatcatccegtatgaaggtctgagcggcgaccaaatgggccagatcgaaaaaattttaaggtggtgtaccetgtggatgatcatcacttta aggtgatcctgcactatggcacactggtaatcgacggggttacgccgaacatgatcgactatttcggacggcegtatgaaggcatcgecgtgttcgac ggcaaaaagatcactgtaacagggaccetgtggaacggcaacaaaattatcgacgagcgectgatcaaccccgacggetccetgctgttccgagtaa ccatcaacggagtgaccggctggcggetgtgcgaacgcattctggcgtaagaaaggaaggaatcgaacccctaaaattggtttcaagccaatctcat atcctatatgtctttctcaataagatattagtaaaatcaattacataactttgtcaaagttaaattatagatcaataatctatatatcttatctgcag - (3' Sma I) 
Sequence S2 for pSV40-mtLuc(CGG). The DNA sequence contains the SV40 promoter [highlighted in green], the ND4 gene [highlighted in gray], the sequence corresponding to FLAG [highlighted in yellow], mtLuc (CGG) gene [highlighted in aqua] and tRNA ${ }^{\text {Asp }}$ gene with the 5'UTR [highlighted in pink]. The SV40 promoter was derived from pGL3-Control (GenBank: U47296.2) to bases 48-250. The ND4 gene, tRNA $^{\text {Asp }}$ gene with the 5'UTR were derived from mouse mtDNA corresponding to bases 10,168-11,544 and bases 6,873-7,011 (GenBank: JF286601.1), respectively. The mtLuc (CGG) gene was synthesized by inserting a point mutation shown in UPPER CASE letters into the Nanoluc luciferase gene of pNL1.1[Nluc] corresponding to bases 100-615 (GenBank: JQ437370.1).

(5'EcoRI) -

ctgcagtgcatctcaattagtcagcaaccatagtccegeccetaactccgeccatccegeccetaactccgeccagttccgeccattctcegecccatcg ctgactaatttttttatttatgcagaggccgaggecgectcggectctgagctattccagaagtagtgaggaggctttttggaggectaggcttttgcaaa aagcttatgctaaaaattattcttccetcactaatgctactaccactaacctgactatcaagccctaaaaaaacctgaacaaacgtaacctcatatagttttct aattagtttaaccagectaacacttctatgacaaaccgacgaaaattataaaaacttttcaaatatattctcctcagaccccctatccacaccattaattatttt aacagcctgattactgccactaatattaatagctagccaaaaccacctaaaaaaagataataacgtactacaaaaactctacatctcaatactaatcagctt acaaattctcctaatcataaccttttcagcaactgaactaattatattttatattttatttgaagcaaccttaatcccaacacttattattattaccegatgaggga accaaactgaacgcctaaacgcagggatttatttcctattttataccctaatcggttctattccactgctaattgecetcatcttaatccaaaaccatgtagga accctaaacctcataattttatcattcacaacacacaccttagacgcttcatgatctaacaacttactatggttggcatgcataatagcatttcttattaaaata ccattatatggagttcacctatgactaccaaaagcccatgttgaagctccaattgctgggtcaataattctagcagctattcttctaaaattaggtagttacg gaataattcgcatctccattattctagacccactaacaaaatatatagcataccecttcatccttctctccctatgaggaataattataactagctcaatctgct tacgccaaacagatttaaaatcactaatcgcctactcctcagttagccacatagcacttgttattgcatcaatcataatccaaactccatgaagcttcatagg agcaacaatactaataatcgcacatggcctcacatcatcactcctattctgcctagcaaactccaactacgaacggatccacagccgtactataatcatg gcccgaggacttcaaatggtcttcccacttatagccacatgatgactgatagcaagtctagctaatctagctctacccccttcaatcaatctaataggaga attattcattaccatatcattattttcttgatcaaactttaccattattcttataggaattaacattattattacaggtatatactcaatatacataattattaccaccc aacgcggcaaactaaccaaccatataattaacctccaaccctcacacacacgagaactaacactaatagcccttcacataattccacttattcttctaacta ccaatccaaaactaattacaggectgacaatagattacaaggatgacgacgataagatggtcttcacactcgaagatttcgttggggactgA cgacag acagccggctacaacctggaccaagtccttgaacagggaggtgtgtccagtttgtttcagaatctcggggtgtccgtaactccgatccaa Cggattgtc ctgagcggtgaaaatgggctgaagatcgacatccatgtcatcatcc cgtatgaaggtctgagcggcgaccaaatgggccagatcgaaaaaattttaa ggtggtgtaccctgtggatgatcatcactttaaggtgatcctgcactatggcacactggtaatcgacggggttacgccgaacatgatcgactatttcgga cggccgtatgaaggcatcgecgtgttcgacggcaaaaagatcactgtaacagggaccetgtggaacggcaacaaaattatcgacgagcgectgatc aacccegacggctccetgctgttccgagtaaccatcaacggagtgaccggctggcggctgtgcgaacgcattctggcgtaagaaaggaaggaatcg aacccctaaaattggtttcaagccaatctcatatcctatatgtctttctcaataagatattagtaaaatcaattacataactttgtcaaagttaaattatagatca ataatctatatatcttatctgcag - (3’Sma I) 
Sequence S3 for pRSV-mtLuc(CGG). The DNA sequence contains the RSV promoter [highlighted in green], ND4 gene [highlighted in gray], the sequence corresponding to FLAG [highlighted in yellow], the mtLuc (CGG) gene [highlighted in aqua] and tRNA ${ }^{\text {Asp }}$ gene with the 5'UTR [highlighted in pink]. The RSV promoter was derived from pRc/RSV (Thermo Fisher Scientific Life Sciences, Waltham, MA) to bases 81-602. The ND4 gene, tRNA Asp gene with the 5'UTR were derived from mouse mtDNA corresponding to bases 10,168-11,544 and bases 6,873-7,011 (GenBank: JF286601.1), respectively. The mtLuc (CGG) gene was synthesized by inserting a point mutation shown in UPPER CASE letters into Nanoluc luciferase gene of pNL1.1[Nluc] corresponding to bases 100-615 (GenBank: JQ437370.1).

(5'EcoRI) -

ctgcagctgctccetgcttgtgtgttggaggtcgctgagtagtgcgcgagcaaaatttaagctacaacaaggcaaggettgaccgacaattgcatgaag aatctgcttagggttaggcgttttgcgctgcttcgcgatgtacgggccagatatacgcgtatctgaggggactagggtgtgtttaggcgaaaagcgggg cttcggttgtacgcggttaggagtcccctcaggatatagtagtttcgcttttgcatagggagggggaaatgtagtcttatgcaatacacttgtagtcttgcaa catggtaacgatgagttagcaacatgccttacaaggagagaaaaagcaccgtgcatgccgattggtggaagtaaggtggtacgatcgtgccttattag gaaggcaacagacaggtctgacatggattggacgaaccactgaattccgcattgcagagataattgtatttaagtgcctagctcgatacaataaacgec atttgaccattcaccacattggtgtgcaccatgctaaaaattattcttcctcactaatgctactaccactaacctgactatcaagccctaaaaaaacctgaa caaacgtaacctcatatagttttctaattagtttaaccagcctaacacttctatgacaaaccgacgaaaattataaaaacttttcaaatatattctcctcagacc ccctatccacaccattaattattttaacagcctgattactgccactaatattaatagctagccaaaaccacctaaaaaaagataataacgtactacaaaaact ctacatctcaatactaatcagcttacaaattctcctaatcataaccttttcagcaactgaactaattatattttatattttatttgaagcaaccttaatcccaacact tattattattaccegatgagggaaccaaactgaacgectaaacgcagggatttatttcctatttataccetaatcggttctattccactgetaattgecetcat cttaatccaaaaccatgtaggaaccctaaacctcataattttatcattcacaacacacaccttagacgcttcatgatctaacaacttactatggttggcatgc ataatagcatttcttattaaaataccattatatggagttcacctatgactaccaaaagcccatgttgaagctccaattgctgggtcaataattctagcagctatt cttctaaaattaggtagttacggaataattcgcatctccattattctagacccactaacaaaatatatagcatacccettcatccttctctccetatgaggaata attataactagctcaatctgcttacgccaaacagatttaaaatcactaatcgectactcctcagttagccacatagcacttgttattgcatcaatcataatcca aactccatgaagcttcataggagcaacaatactaataatcgcacatggectcacatcatcactcctattctgcctagcaaactccaactacgaacggatc cacagccgtactataatcatggccegaggacttcaaatggtcttcccacttatagccacatgatgactgatagcaagtctagctaatctagctctaccccc ttcaatcaatctaataggagaattattcattaccatatcattattttcttgatcaaactttaccattattcttataggaattaacattattattacaggtatatactcaa tatacataattattaccacccaacgcggcaaactaaccaaccatataattaacctccaaccctcacacacacgagaactaacactaatagccettcacata attccacttattcttctaactaccaatccaaaactaattacaggcetgacaatagattacaaggatgacgacgataagatggtcttcacactcgaagatttc gttggggactgAcgacagacagccggctacaacctggaccaagtccttgaacagggaggtgtgtccagtttgtttcagaatctcggggtgtccgtaa ctccgatccaa Cggattgtcctgagcggtgaaaatgggetgaagatcgacatccatgtcatcatccegtatgaaggtctgagcggcgaccaaatggg ccagatcgaaaaaatttttaaggtggtgtacctgtggatgatcatcactttaaggtgatcctgcactatggcacactggtaatcgacggggttacgecga acatgatcgactatttcggacggecgtatgaaggcatcgccgtgttcgacggcaaaaagatcactgtaacagggaccetgtggaacggcaacaaaatt atcgacgagcgectgatcaacccegacggctcc tgctgttccgagtaaccatcaacggagtgaccggctggeggetgtgcgaacgcattctggcgt aagaaaggaaggaatcgaacccctaaaattggtttcaagccaatctcatatcctatatgtctttctcaataagatattagtaaaatcaattacataactttgt caaagttaaattatagatcaataatctatatatcttatctgcag - (3’ Sma I) 
Sequence S4 for pT7-mtLuc(CGG). The DNA sequence contains the T7 promoter [highlighted in green], ND4 gene [highlighted in gray], the sequence corresponding to FLAG [highlighted in yellow], the mtLuc (CGG) gene [highlighted in aqua] and the tRNA ${ }^{\text {Asp }}$ gene with the 5'UTR [highlighted in pink]. The T7 promoter was derived from pBluescript II SK (+) (Stratagene) to bases 626-644. The ND4 gene, tRNA ${ }^{\text {Asp }}$ gene with the 5'UTR were derived from mouse mtDNA corresponding to bases 10,168-11,544 and bases 6,873-7,011 (GenBank: JF286601.1), respectively. The mtLuc (CGG) gene was synthesized by inserting a point mutation shown in UPPER CASE letters into the Nanoluc luciferase gene of pNL1.1[Nluc] corresponding to bases 100-615 (GenBank: JQ437370.1).

(5'EcoRI) -

ctgcagtaatacgactcactatagggatgctaaaaattattcttccetcactaatgctactaccactaacctgactatcaagccctaaaaaacctgaacaa acgtaacctcatatagttttctaattagtttaaccagcctaacacttctatgacaaaccgacgaaaattataaaaacttttcaaatatattctcctcagacccc tatccacaccattaattattttaacagcctgattactgccactaatattaatagctagccaaaaccacctaaaaaaagataataacgtactacaaaaactcta catctcaatactaatcagcttacaaattctcctaatcataaccttttcagcaactgaactaattatattttatattttatttgaagcaaccttaatcccaacacttatt attattacccgatgagggaaccaaactgaacgectaaacgcagggatttatttcctattttataccctaatcggttctattccactgctaattgccetcatctta atccaaaaccatgtaggaaccctaaacctcataattttatcattcacaacacacaccttagacgcttcatgatctaacaacttactatggttggcatgcataa tagcatttcttattaaaataccattatatggagttcacctatgactaccaaaagcccatgttgaagctccaattgctgggtcaataattctagcagctattcttc taaaattaggtagttacggaataattcgcatctccattattctagacccactaacaaaatatatagcatacccettcatcettctctccetatgaggaataatta taactagctcaatctgcttacgccaaacagatttaaaatcactaatcgectactcctcagttagccacatagcacttgttattgcatcaatcataatccaaact ccatgaagcttcataggagcaacaatactaataatcgcacatggcctcacatcatcactcctattctgcctagcaaactccaactacgaacggatccaca gccgtactataatcatggeccgaggacttcaaatggtcttcccacttatagccacatgatgactgatagcaagtctagctaatctagctctaccccttcaa tcaatctaataggagaattattcattaccatatcattatttcttgatcaaactttaccattattcttataggaattaacattattattacaggtatatactcaatatac ataattattaccacccaacgcggcaaactaaccaaccatataattaacctccaaccctcacacacacgagaactaacactaatagccettcacataattcc acttattcttctaactaccaatccaaaactaattacaggcctgacaatagattacaaggatgacgacgataagatggtcttcacactcgaagatttcgttgg ggactgAcgacagacagccggctacaacctggaccaagtccttgaacagggaggtgtgtccagtttgtttcagaatctcggggtgtccgtaactccg atccaa Cggattgtcctgagcggtgaaaatgggetgaagatcgacatccatgtcatcatccegtatgaaggtctgagcggcgaccaaatgggccaga tcgaaaaaatttttaaggtggtgtaccctgtggatgatcatcactttaaggtgatcctgcactatggcacactggtaatcgacggggttacgccgaacatg atcgactatttcggacggccgtatgaaggcatcgccgtgttcgacggcaaaaagatcactgtaacagggaccetgtggaacggcaacaaaattatcga cgagcgectgatcaacccegacggctccetgctgttccgagtaaccatcaacggagtgaccggetggcggetgtgcgaacgcattctggcgtaagaa aggaaggaatcgaaccccctaaaattggtttcaagccaatctcatatcctatatgtctttctcaataagatattagtaaaatcaattacataactttgtcaaagt taaattatagatcaataatctatatatcttatctgcag - (3’Sma I) 
Sequence S5 for pCMV-mtLuc(CGG) [hND4]. The DNA sequence contains the CMV promoter [highlighted in green], the human ND4 gene [highlighted in gray], the sequence corresponding to FLAG [highlighted in yellow], the mtLuc (CGG) gene [highlighted in aqua] and the tRNA ${ }^{\text {Asp }}$ gene with the 5 'UTR [highlighted in pink]. The CMV promoter was derived from pTriEx-3 Neo Vector (Promega, Madison, WI, USA) to bases 1,021-1,596. The human ND4 gene was derived from human mtDNA corresponding to bases 10,760-12,136 (GenBank: NC_012920.1). The tRNA Asp gene with the 5'UTR was derived from mouse mtDNA corresponding to bases 6,873-7,011 (GenBank: JF286601.1). The mtLuc (CGG) gene was synthesized by inserting a point mutation shown in UPPER CASE letters into the Nanoluc luciferase gene of pNL1.1[Nluc] corresponding to bases 100-615 (GenBank: JQ437370.1).

(5'EcoRI) -

ctgcagattaatagtaatcaattacggggtcattagttcatagcccatatatggagttccgcgttacataacttacggtaaatggecegcetggctgaccg cccaacgaccccgeccattgacgtcaataatgacgtatgttcccatagtaacgecaatagggactttccattgacgtcaatgggtggagtatttacggt aaactgeccacttggcagtacatcaagtgtatcatatgccaagtccgecccetattgacgtcaatgacggtaaatggeccgectggcattatgeccagta catgaccttacgggactttcctacttggcagtacatctacgtattagtcatcgctattaccatgctgatgcggttttggcagtacaccaatgggcgtggata gcggtttgactcacggggatttccaagtctccaccccattgacgtcaatgggagtttgttttggcaccaaaatcaacgggactttccaaaatgtcgtaata acccegcccgttgacgcaaatgggeggtaggcgtgtacggtgggaggtctatataagcagacgtcgtttagtgaaccatgctaaaactaatcgtccc aacaattatattactaccactgacatgactttccaaaaaacacataatttgaatcaacacaaccacccacagcctaattattagcatcatccetctactattttt taaccaaatcaacaacaacctatttagctgttccccaaccttttcctccgaccccctaacaaccccectcctaatactaactacctgactcctacccetcac aatcatggcaagccaacgccacttatccagtgaaccactatcacgaaaaaactctacctctctatactaatctccctacaaatctccttaattataacattc acagccacagaactaatcatattttatatcttcttcgaaaccacacttatcccacettggctatcatcaccegatgaggcaaccagccagaacgectgaa cgcaggcacatacttcctattctacaccetagtaggctccettcccetactcatcgcactaatttacactcacaacaccetaggctcactaaacattctacta ctcactctcactgcccaagaactatcaaactcctgagccaacaacttaatatgactagcttacacaatagcttttatagtaaagatacctctttacggactcc acttatgactccctaaagcccatgtcgaagccccatcgetgggtcaatagtacttgccgcagtactcttaaaactaggcggctatggtataatacgectc acactcattctcaacccctgacaaaacacatagcctacccettccttgtactatccetatgaggcataattataacaagctccatctgcctacgacaaaca gacctaaaatcgctcattgcatactcttcaatcagccacatagccetcgtagtaacagccattctcatccaaaccccetgaagettcaccggcgcagtcat tctcataatcgeccacgggettacatcctcattactattctgectagcaaactcaaactacgaacgcactcacagtcgcatcataatcctctctcaaggact tcaaactctactcccactaatagcttttgatgacttctagcaagcctcgctaacctcgecttaccccccactattaacctactgggagaactctctgtgcta gtaaccacgttctcctgatcaaatatcactctcctacttacaggactcaacatactagtcacagccctatactccetctacatattaccacaacacaatggg gctcactcacccaccacattaacaacataaaaccctcattcacacgagaaaacaccetcatgttcatacacctatcccccattctcctcctatccetcaacc ccgacatcattaccgggttttcctctgattacaaggatgacgacgataagatggtcttcacactcgaagatttcgttggggactgAcgacagacagccg gctacaacctggaccaagtccttgaacagggaggtgtgtccagtttgtttcagaatctcggggtgtccgtaactccgatccaa Cggattgtcctgagcg gtgaaaatgggctgaagatcgacatccatgtcatcatcccgtatgaaggtctgagcggcgaccaaatgggccagatcgaaaaaatttttaaggtggtgt accetgtggatgatcatcactttaaggtgatcctgcactatggcacactggtaatcgacggggttacgecgaacatgatcgactatttcggacggecgta tgaaggcatcgecgtgttcgacggcaaaaagatcactgtaacagggaccetgtggaacggcaacaaaattatcgacgagcgectgatcaacccega cggctccetgctgttccgagtaaccatcaacggagtgaccggctggcggetgtgcgaacgcattctggcgtaagaaaggaaggaatcgaaccccta aaattggtttcaagccaatctcatatcctatatgtctttctcaataagatattagtaaaatcaattacataactttgtcaaagttaaattatagatcaataatctata tatcttatctgcag - (3’'Sma I) 
Sequence S6 for pCMV-mtLuc(CGG) [-ND4]. The DNA sequence contains the CMV promoter [highlighted in green] the sequence corresponding to FLAG [highlighted in yellow], the mtLuc (CGG) gene [highlighted in aqua] and the tRNA ${ }^{\text {Asp }}$ gene with the 5'UTR [highlighted in pink]. The CMV promoter was derived from pTriEx-3 Neo Vector (Promega, Madison, WI, USA) to bases 1,021-1,596. The tRNA ${ }^{\text {Asp }}$ gene with the 5'UTR was derived from mouse mtDNA corresponding to bases 6,873-7,011 (GenBank: JF286601.1). The mtLuc (CGG) gene was synthesized by inserting a point mutation shown in UPPER CASE letters into the Nanoluc luciferase gene of pNL1.1[Nluc] corresponding to bases 100-615 (GenBank: JQ437370.1).

(5'EcoRI) -

ctgcagattaatagtaatcaattacggggtcattagttcatagcccatatatggagttccgcgttacataacttacggtaaatggecegectggetgaccg

cccaacgaccccgeccattgacgtcaataatgacgtatgttcccatagtaacgccaatagggactttccattgacgtcaatgggtggagtatttacggt

aaactgeccacttggcagtacatcaagtgtatcatatgccaagtccgcccctattgacgtcaatgacggtaaatggecegectggcattatgcccagta

catgaccttacgggactttcctacttggcagtacatctacgtattagtcatcgctattaccatgctgatgcggtttggcagtacaccaatgggegtggata

gcggtttgactcacggggatttccaagtctccaccccattgacgtcaatgggagtttgtttggcaccaaaatcaacgggactttccaaaatgtcgtaata

acccegcccegttgacgcaaatgggcggtaggcgtgtacggtgggaggtctatataagcagacgtcgtttagtgaaccatggtcttcacactcgaaga tttcgttggggactgA cgacagacagccggctacaacctggaccaagtccttgaacagggaggtgtgtccagtttgtttcagaatctcggggtgtccg taactccgatccaa Cggattgtcctgagcggtgaaaatgggctgaagatcgacatccatgtcatcatccegtatgaaggtctgagcggcgaccaaatg ggccagatcgaaaaaattttaaggtggtgtaccetgtggatgatcatcactttaaggtgatcctgcactatggcacactggtaatcgacggggttacgec gaacatgatcgactatttcggacggecgtatgaaggcatcgccgtgttcgacggcaaaaagatcactgtaacagggaccetgtggaacggcaacaaa attatcgacgagcgcctgatcaaccccgacggctccetgctgttccgagtaaccatcaacggagtgaccggctggcggctgtgcgaacgcattctgg cgtaagaaaggaaggaatcgaaccccctaaaattggtttcaagccaatctcatatcctatatgtcttctcaataagatattagtaaaatcaattacataactt tgtcaaagttaaattatagatcaataatctatatatcttatctgcag - (3’Sma I) 
Sequence $\mathbf{S 7}$ for pCMV-mtLuc(TAG). The DNA sequence contains the CMV promoter [highlighted in green], ND4 gene [highlighted in gray], the sequence corresponding to FLAG [highlighted in yellow], the mtLuc (TAG) gene [highlighted in aqua] and the tRNA Asp gene with the 5'UTR [highlighted in pink]. The CMV promoter was derived from pTriEx-3 Neo Vector (Promega, Madison, WI, USA) to bases 1,021-1,596. The ND4 gene, the tRNA ${ }^{\text {Asp }}$ gene with the 5'UTR were derived from mouse mtDNA corresponding to bases 10,168-11,544 and bases 6,873-7,011 (GenBank: JF286601.1), respectively. The mtLuc (TAG) gene was synthesized by inserting a point mutation, shown in UPPER CASE letters into the Nanoluc luciferase gene of pNL1.1[Nluc] corresponding to bases 100-615 (GenBank: JQ437370.1). We previously reported this sequence information in reference [1].

(5’ECORI) -

ctgcagattaatagtaatcaattacggggtcattagttcatagcccatatatggagttccgcgttacataacttacggtaaatggecegectggetgaccg cccaacgaccccecccattgacgtcaataatgacgtatgttcccatagtaacgecaatagggactttccattgacgtcaatgggtggagtatttacggt aaactgcccacttggcagtacatcaagtgtatcatatgccaagtccgeccctattgacgtcaatgacggtaaatggeccgectggcattatgeccagta catgaccttacgggactttcctacttggcagtacatctacgtattagtcatcgctattaccatgctgatgcggttttggcagtacaccaatgggcgtggata gcggtttgactcacggggatttccaagtctccaccccattgacgtcaatgggagtttgttttggcaccaaaatcaacgggactttccaaaatgtcgtaata acccegcccegttgacgcaaatgggcggtaggcgtgtacggtgggaggtctatataagcagacgtcgtttagtgaaccatgctaaaaattattcttccet cactaatgctactaccactaacctgactatcaagcctaaaaaaacctgaacaaacgtaacctcatatagttttctaattagtttaaccagcctaacacttct atgacaaaccgacgaaaattataaaaacttttcaaatatattctcctcagacccctatccacaccattaattattttaacagcetgattactgecactaatatt aatagctagccaaaaccacctaaaaaaagataataacgtactacaaaaactctacatctcaatactaatcagcttacaaattctcctaatcataaccttttca gcaactgaactaattatattttatattttatttgaagcaaccttaatcccaacacttattattattaccegatgagggaaccaaactgaacgcctaaacgcagg gatttatttcctattttataccctaatcggttctattccactgctaattgecetcatcttaatccaaaaccatgtaggaaccctaaacctcataattttatcattcac aacacacaccttagacgettcatgatctaacaacttactatggttggcatgcataatagcatttcttattaaaataccattatatggagttcacctatgactacc aaaagcccatgttgaagctccaattgctgggtcaataattctagcagctattcttctaaaattaggtagttacggaataattcgcatctccattattctagacc cactaacaaaatatatagcataccccttcatccttctctccctatgaggaataattataactagctcaatctgcttacgecaaacagatttaaaatcactaatc gcctactcctcagttagccacatagcacttgttattgcatcaatcataatccaaactccatgaagcttcataggagcaacaatactaataatcgcacatggc ctcacatcatcactcctattctgcctagcaaactccaactacgaacggatccacagccgtactataatcatggeccgaggacttcaaatggtcttccact tatagccacatgatgactgatagcaagtctagctaatctagctctaccccettcaatcaatctaataggagaattattcattaccatatcattatttcttgatca aactttaccattattcttataggaattaacattattattacaggtatatactcaatatacataattattaccacccaacgcggcaaactaaccaaccatataatta acctccaaccctcacacacacgagaactaacactaatagccttcacataattccacttattcttctaactaccaatccaaaactaattacaggcctgacaa tagattacaaggatgacgacgataagatggtcttcacactcgaagatttcgttggggactgAcgacagacagccggctacaacctggaccaagtcctt gaacagggaggtgtgtccagtttgtttcagaatctcggggtgtccgtaactccgatccaa/Agattgtcctgagcggtgaaaatgggetgaagatcga catccatgtcatcatccegtatgaaggtctgagcggcgaccaaatgggccagatcgaaaaaatttttaaggtggtgtaccetgtggatgatcatcacttta aggtgatcctgcactatggcacactggtaatcgacggggttacgccgaacatgatcgactatttcggacggecgtatgaaggcatcgecgtgttcgac ggcaaaaagatcactgtaacagggaccetgtggaacggcaacaaaattatcgacgagcgcctgatcaacccegacggctccetgctgttccgagtaa c catcaacggagtgaccggctggcggctgtgcgaacgcattctggcgtaagaaaggaaggaatcgaacccctaaaattggtttcaagccaatctcat atcctatatgtctttctcaataagatattagtaaaatcaattacataactttgtcaaagttaaattatagatcaataatctatatatcttatctgcag - (3' Sma I) 


\section{References}

[1] Yamada Y, Ishikawa T, Harashima H. Validation of the use of an artificial mitochondrial reporter DNA vector containing a Cytomegalovirus promoter for mitochondrial transgene expression. Biomaterials. in press. 